\title{
Article \\ Combination of Resminostat with Ruxolitinib Exerts Antitumor Effects in the Chick Embryo Chorioallantoic Membrane Model for Cutaneous T Cell Lymphoma
}

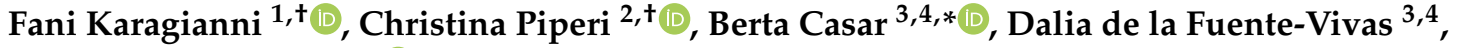 \\ Rocío García-Gómez ${ }^{3,4}{ }^{1}$, Kyriaki Lampadaki ${ }^{1}$, Vasiliki Pappa ${ }^{5}$ and Evangelia Papadavid ${ }^{1, *}$
}

check for updates

Citation: Karagianni, F.; Piperi, C.; Casar, B.; de la Fuente-Vivas, D.; García-Gómez, R.; Lampadaki, K.; Pappa, V.; Papadavid, E.

Combination of Resminostat with Ruxolitinib Exerts Antitumor Effects in the Chick Embryo Chorioallantoic Membrane Model for Cutaneous T Cell Lymphoma. Cancers 2022, 14, 1070. https://doi.org/10.3390/ cancers14041070

Academic Editor: Matthias Goebeler

Received: 25 January 2022

Accepted: 16 February 2022

Published: 20 February 2022

Publisher's Note: MDPI stays neutral with regard to jurisdictional claims in published maps and institutional affiliations.

Copyright: (C) 2022 by the authors. Licensee MDPI, Basel, Switzerland. This article is an open access article distributed under the terms and conditions of the Creative Commons Attribution (CC BY) license (https:// creativecommons.org/licenses/by/ $4.0 /)$.
1 National Center of Rare Diseases-Cutaneous Lymphoma-Member of EuroBloodNet, Second Department of Dermatology and Venereal Diseases, Attikon University General Hospital, National and Kapodistrian University of Athens, 12462 Athens, Greece; karagiannifani@gmail.com (F.K.); sundylam@yahoo.gr (K.L.)

2 Department of Biological Chemistry, Medical School of Athens, National and Kapodistrian University of Athens, 11527 Athens, Greece; cpiperi@med.uoa.gr

3 Instituto de Biomedicina y Biotecnología de Cantabria, Consejo Superior de Investigaciones Científicas (CSIC)-Universidad de Cantabria, 39011 Santander, Spain; daliadelafuentevivas@gmail.com (D.d.l.F.-V.); rocio.garciagomez@unican.es (R.G.-G.)

4 Centro de Investigación Biomédica en Red de Cáncer (CIBERONC), Instituto de Salud Carlos III, 28029 Madrid, Spain

5 2nd Department of Internal Medicine-Propaedeutic and Research Unit, National and Kapodistrian University of Athens, Medical School of Athens, University General Hospital Attikon, 12462 Athens, Greece; vas_pappa@yahoo.com

* Correspondence: berta.casar@unican.es (B.C.); epapad@med.uoa.gr (E.P.)

$\dagger$ These authors contributed equally to this work.

Simple Summary: The combination of Resminostat (HDACi) and Ruxolitinib (JAKi) exerted cytotoxic effects and inhibited proliferation of CTCL cell lines (MyLa, SeAx) in vitro. The aim of the present study was to validate their antitumor effects in vivo using the chick embryo chorioallantoic membrane (CAM) model, which allows quick and efficient monitoring of tumor growth, migration, invasion, and metastatic potential. The drug combination exhibited a significant inhibition of primary tumor size, and inhibited intravasation and extravasation of tumor cells to the liver and lung. It also exerted an inhibitory effect in the migration and invasion of tumor cells and significantly reduced key signaling pathway activation. Our data demonstrate that the CAM assay could be employed as a preclinical in vivo model in CTCL for pharmacological testing, and that the combination of Resminostat and Ruxolitinib exerts significant antitumor effects in CTCL progression that need to be further evaluated in a clinical setting.

\begin{abstract}
The combination of Resminostat (HDACi) and Ruxolitinib (JAKi) exerted cytotoxic effects and inhibited proliferation of CTCL cell lines (MyLa, SeAx) in previously published work. A xenograft tumor formation was produced by implanting the MyLa or SeAx cells on top of the chick embryo chorioallantoic membrane (CAM). The CAM assay protocol was developed to monitor the metastatic properties of CTCL cells and the effects of Resminostat and/or Ruxolitinib in vivo. In the spontaneous CAM assays, Resminostat and Ruxolitinib treatment inhibited the cell proliferation $(p<0.001)$ of MyLa and SeAx, and induced cell apoptosis ( $p<0.005, p<0.001$, respectively). Although monotherapies reduced the size of primary tumors in the metastasis CAM assay, the drug combination exhibited a significant inhibition of primary tumor size $(p<0.0001)$. Furthermore, the combined treatment inhibited the intravasation of MyLa $(p<0.005)$ and SeAx cells $(p<0.0001)$ in the organs, as well as their extravasation to the liver $(p<0.0001)$ and lung $(p<0.0001)$. The drug combination also exerted a stronger inhibitory effect in migration $(p<0.0001)$ rather in invasion $(p<0.005)$ of both MyLa and SeAx cells. It further reduced p-p38, p-ERK, p-AKT, and p-STAT in MyLa cells, while it decreased p-ERK and p-STAT in SeAx cells in CAM tumors. Our data demonstrated that the CAM assay could be employed as a preclinical in vivo model in CTCL for pharmacological testing. In agreement with previous in vitro data, the combination of Resminostat and Ruxolitinib was shown to exert antitumor effects in CTCL in vivo.
\end{abstract}


Keywords: chicken chorioallantoic membrane; CAM; MyLa; SeAx; Resminostat; Ruxolitinib; JAKi; HDACi; intravasation; extravasation; metastasis

\section{Introduction}

Cutaneous T-cell Lymphomas (CTCLs) present a diverse group of extra-nodal nonHodgkin lymphomas characterized by clonal growth of malignant T cells in the skin [1]. The most common type of CTCL is Mycosis Fungoides (MF), which is characterized by patches, infiltrated plaques, or tumors [2], whereas Sezary Syndrome (SS) is characterized by erythroderma, lymphadenopathy, and the presence of a malignant $\mathrm{T}$ cell clone in the peripheral blood and skin [3,4]. MF/SS are incurable and generally lethal in advanced stages [5], characterized by a chronic, relapsing course that necessitates repeat treatment regimens [6]. It is critical to establish new regimens for MF/SS patients with long-lasting and tolerable responses. Therapeutic strategies that combine novel agents with current treatment options may prove beneficial in the future management of CTCL patients [7]. To this end, there is a need for better understanding of the major biological mechanisms underlying CTCL to develop more effective treatments and improve patients' survival [8].

The combinational use of multiple epigenetic modulators simultaneously or in conjunction with other treatments has been demonstrated to be effective in preclinical and clinical studies [9-13]. Combinational therapies that target several signaling pathways and clonal subpopulations can increase the survival and quality of life of patients [14]. An example of a combinational therapy involving existing drugs is the use of JAK/HDAC inhibitors, which have already been employed in haematological malignancies, presenting a prospective therapeutic target for CTCL. Recent NGS data, including single-cell sequencing, have uncovered genetic abnormalities in critical signaling networks and epigenetic components that play a significant role in CTCL pathogenesis [14]. High-throughput screening has become a popular tool to quickly identify and prioritize new medicinal molecules. Several studies on CTCL have used high-throughput technology, next-generation sequencing (NGS), and whole genome sequencing (WGS) techniques to detect potential key signaling pathways and targets [15-17]. Activation of the JAK-STAT pathway has been mostly associated with the pathogenesis and progression of CTCL, as well as some other hematologic malignancies $[18,19]$. Previous in vitro data from our group have shown that the combination of Resminostat (HDACi) with Ruxolitinib (JAKi) exhibited cytotoxic effects in CTCL cell lines, and inhibited cell proliferation, suggesting a strong synergy of the two drugs [20]. The drug combination inhibited phosphorylation of STAT3, AKT, ERK1/2, and JNK in MyLa cells, while it reduced activation of AKT and JNK in SeAx. However, there are few in vivo CTCL models to validate the potential therapeutic impact of new agents.

In the present study, we have initially investigated the preclinical experimental model by implanting MF/SS cells in the Chick Embryo Chorioallantoic Membrane (CAM) [21,22]. This experimental model has become an appealing tool for in vivo assays for drug testing, tumor growth, and metastasis [23]. The chick embryo is a naturally immunodeficient model and it can be used as a Sezary model to study the tumor microenvironment in CTCL during the early stages. The immune system of chicks does not begin to function until they are about 2 weeks old [24,25]. T cells appear at day 11 and B cells at day 12 [26], and chick embryos are immunocompetent by day 18 [24,25]. Chick CAM allows the fast vascularization of tumors placed on its surface. More specifically, CAM vasculature is attracted to grow into the developing tumor depending on the aggressiveness of the tumor cells, which then intravasate into the blood vessels. Unlike normal mouse models, most cancer cells arrested in the CAM microcirculation survive without causing cell injury, and a considerable number complete extravasation within $24 \mathrm{~h}$ following injection [27]. In comparison to mammalian models, where tumor growth takes 3 to 6 weeks, chick CAM is faster: microtumors appear 2 to 5 days after tumor cell transplantation. Finally, the model's ease of use and low cost make it more appealing. Because of the short time 
(8-10 days) between implantation and chick hatching, most tumor cells are unable to develop macroscopic visible colonies in secondary organs in the CAM model [28].

Xenografted tumors from MyLa and SeAx cells implanted on the top of CAM were studied in order to assess CAM as a pre-clinical CTCL model for pharmacological testing. Based on our in vitro findings [20], we investigated the potential anti-tumor effects of JAKi/HDACi, Resminostat, and/or Ruxolitinib. Our data suggest that the CAM assay presents a promising CTCL pre-clinical model for testing future therapeutic agents.

\section{Materials and Methods}

\subsection{Cell Lines and Culturing}

The human CTCL cell lines, MyLa and SeAx, were kindly provided by Dr Michel Laurence (Skin Research Center Service de Dermatologie Hôpital Saint-Louis, INSERM, Paris, France), which were already tested and authenticated. Both cell lines were cultured in RPMI 1640, supplemented with $10 \%$ fetal bovine serum and $1 \%$ penicillin/streptomycin, at $37^{\circ} \mathrm{C}$ in a humidified atmosphere with $5 \% \mathrm{CO}_{2}$, for $24 \mathrm{~h}$.

\subsection{Drugs Tested}

The HDAC inhibitor was a generous gift from 4SC AG (Planegg-Martinsried, Germany) and the JAK inhibitor was a gift from Novartis Incyte (Basel, Switzerland). Both inhibitors were dissolved in DMSO according to the manufacturers' instructions. Therefore, vehicle controls or untreated cells were treated with $0.1 \%$ DMSO for all the experiments.

\subsection{Chick Embryo CAM Model: Xenografted Tumours and Spontaneous Metastasis}

The chick embryo CAM model was developed as previously described [21,22], by first preparing the eggs for xenografting tumor cells, then preparing tumor cells for grafting, grafting the tumor cells onto the CAM, and, finally, harvesting tumors and chick embryo tissues. More specifically, $10^{6} \mathrm{MyLa}$ or SeAx cells were injected onto CAM embryos and induced tumor formation. Tumor growth was monitored, and spontaneous metastasis was initiated in chick embryos. An amount of $15 \mu \mathrm{M}$ Ruxolitinib and $5 \mu \mathrm{M}$ Resminostat were administered topically every two days. Harvesting was performed on day 7 and the numbers of tumor cells on the CAM, liver, and lung were analyzed by Alu PCR, along with their effects on cell viability and apoptosis.

The chick embryo CAM assay did not require administrative procedures for obtaining ethics committee approval for animal experimentation, since the chick embryo is not considered as a living animal until day 17 of development. The CAM was not innervated, and experiments were terminated before the development of centers in the brain associated with pain perception, making this a system not requiring animal experimentation permissions. All experiments were performed according to the national guidelines for animal care in accordance with the European Union Directive.

\subsection{Quantitative Detection of Human Tumor Cell Metastasis}

Genomic DNA was extracted from the harvested tissues using the Qiagen DNA purification system (Qiagen, Hilden, Germany catalog number: 158906;158910;158914). To detect human cells in the chick tissues, primers specific for the human Alu sequences (sense: $5^{\prime}$ ACGCCTGTAATCCCAGGACTT; 3'antisense: $5^{\prime}$ TCGCCCAGGCTGGCTGGGTGCA 3') were used to amplify the human Alu repeats present in genomic DNA that was extracted from chick tissues. The real-time PCR used to amplify and detect Alu sequences contained $30 \mathrm{ng}$ of genomic DNA, $2 \mathrm{~mm} \mathrm{MgCl}_{2}, 0.4 \mu \mathrm{m}$ each primer, $200 \mu \mathrm{m}$ DNTP, 0.4 units of Platinum Taq polymerase (Invitrogen Corporation, Carlsbad, CA, USA), and a 1:100,000 dilution of SYBR green dye (Molecular Probes, Eugene, OR, USA). Each PCR was performed in a final volume of $10 \mu \mathrm{L}$ under $10 \mu \mathrm{L}$ of mineral oil with the iCycler iQ (Bio-Rad laboratories, Hercules, CA, USA) under the following conditions: polymerase activation- $95^{\circ} \mathrm{C}$ for $2 \mathrm{~min}, 40$ cycles at $95^{\circ} \mathrm{C}$ for $30 \mathrm{~s}, 63^{\circ} \mathrm{C}$ for $30 \mathrm{~s}, 72{ }^{\circ} \mathrm{C}$ for $30 \mathrm{~s}$. A quantitative measure of amplifiable chick DNA was obtained through the amplification of the chick GAPDH 
genomic DNA sequence with chGAPDH primers (sense: 5' GAGGAAAGGTCGCCTGGTGGATCG 3'; antisense: $5^{\prime}$ GGTGAGGACAAGCAGTGAGGA ACG $3^{\prime}$ ) using the same PCR conditions as described for Alu. The fluorescence emitted by the reporter dye was detected online in real-time, and the threshold cycle $(\mathrm{Ct})$ of each sample was recorded as a quantitative measure of the amount of PCR product in the sample. The $\mathrm{Ct}$ is the fractional cycle number at which the fluorescence generated by the reporter dye exceeds a fixed level above baseline. When indicated, the Alu signal was normalized against the relative quantity of GAPDH and expressed as $\Delta \mathrm{Ct}=(\mathrm{CtGAPDH}-\mathrm{Ct} \mathrm{Alu})$. The changes in Alu signal relative to the total amount of genomic DNA (and, hence, changes in the quantity of human DNA in the chick tissue) were expressed as $\Delta \Delta \mathrm{CT}=\Delta$ Ctcontrol $-\Delta$ Cttreatment. Relative changes in metastasis were then calculated as $2 \Delta \Delta \mathrm{CT}$. Each assay included a negative control, a positive control, a no-template control, and the experimental samples in triplicate. To approximate the actual number of tumor cells present in each tissue sample, a standard curve was generated through quantitative amplification of genomic DNA extracted from a serial dilution of MyLa and SeAx cells respectively mixed with individual chick lung homogenates. By interpolating the Alu signal from experimental samples with the standard curve, the actual number of tumor cells/lung could be determined over a range of 50-100,000 cells/lung. Data processing and statistical analysis were performed using GraphPad Prism 9 (GraphPad Software Inc., San Diego, CA, USA) and Microsoft Excel 16.3 (Microsoft Corporation, Redmond, WA, USA). The synergistic effect between Resminostat and Ruxolitinib was determined by the combination index (CI) as previously described [29]. The $\mathrm{CI}$ value was determined by the following equation: $\mathrm{CI}=$ sum of tumor growth or metastasis inhibition of single agent treatment/tumor growth or metastasis inhibition upon combined treatment. A combination index (CI) of $>1$ indicates antagonism, a CI of 1 denotes additivity, and a CI of $<1$ indicates synergism. More specifically, CI values ranging from 0.1 to 0.3 are considered to indicate strong synergism, 0.3 to 0.7 synergism, and 0.7 to 0.85 moderate synergism.

\subsection{Experimental Metastasis Chick Embryo Model}

Fertilized chicken eggs were obtained from Gibert farm (Tarragona, Spain) and incubated with rotation at $37.50{ }^{\circ} \mathrm{C}$ and $60 \%$ humidity. On day 12 of incubation, the developing embryos were injected intravenously with $5 \times 10^{4}$ cells in $0.1 \mathrm{~mL}$ serum-free DMEM. At indicated time points, the embryos also either received Resminostat, Ruxolitinib, both, or DMSO as a vehicle. On day 5, portions of the CAM were harvested to perform biochemical analyses and to determine, by Alu qPCR, the number of human tumor cells which had colonized the tissues.

\subsection{Live Cell Imaging}

MyLa and SeAx cells were labeled with $5 \mu \mathrm{mol} / \mathrm{L}$ green CellTracker CMFDA and injected intravenously at $1 \times 10^{5}$ cells per embryo and the indicated concentrations of Resminostat and Ruxolitinib. To highlight vasculature, the embryos were injected with $50 \mu \mathrm{g}$ of Rhodamine-conjugated Lens culinaris agglutinin (LCA, Vector, Burlingame, CA, USA). At $24 \mathrm{~h}$, the embryos were sacrificed; the portions of the CAM were stretched on glass slides and examined in a Carl Zeiss Axio Imager microscope. Digital images were taken with AxioVision Rel. 4.6 software (Carl Zeiss MicroImaging).

\subsection{Proliferation Analyses}

Proliferation assays were performed using AlamarBlue Cell Viability Reagent (Thermo Fisher, Waltham, MA, USA). 5000 cells/well were plated in a 96 well plate in $100 \mu \mathrm{L}$ medium and treated under the desired conditions. After that time, $10 \mu \mathrm{L}$ of AlamarBlue Reagent was added and incubated in the dark at $37^{\circ} \mathrm{C}$ for $12 \mathrm{~h}$. Absorbance was read at 540 and $620 \mathrm{~nm}$. 


\subsection{Apoptosis Assays}

$10^{6}$ cells were collected by centrifugation at $1000 \mathrm{rpm}$ for $5 \mathrm{~min}$ at $4{ }^{\circ} \mathrm{C}$. They were washed with $1 \mathrm{~mL}$ of filtrated $3 \mathrm{mM}$ EDTA PBS and centrifuged again. The pellet was resuspended in $200 \mu \mathrm{L}$ of binding buffer (BB) (10X BB: HEPES 0.1M pH 7.4, NaCl 1.4 M, $\mathrm{CaCl}^{2}$ $25 \mathrm{mM}$ ) and placed in cytometry tubes. Then, $1 \mu \mathrm{L}$ of FITC Annexin V (BD Pharmagen) and $20 \mu \mathrm{L}$ of FBS were added to avoid unspecific interactions. The mix was incubated $30 \mathrm{~min}$ in dark at $4{ }^{\circ} \mathrm{C}$. After incubation, one wash with $1 \mathrm{~mL}$ of $2 \mathrm{mM}$ EDTA PBS was performed, and the cells were collected by centrifugation and resuspended in $200 \mu \mathrm{L}$ of $2 \mathrm{mM}$ EDTA PBS to perform the flow cytometry. Apoptosis rate was determined in MACSQuant VYB (Miltenyi Biotec, Gladbach, Germany) and the results were analyzed with Flow Logic software (Miltenyi Biotec, Gladbach, Germany).

\subsection{Migration Assays}

Cell migration was examined in Transwell cell culture chamber filters ( $8 \mu \mathrm{m}$ pore) (Corning, New York, NY, USA). Green tracker fluorescent-labeled cells were seeded at $5 \times 10^{4}$ cells in RPMI-0.2\% FBS. Following $16 \mathrm{~h}$ incubation, the invading cells were fixed and analyzed by fluorescence microscopy and counted. Images were processed and analyzed using FIJI Image.

\subsection{Invasion Assays}

In Matrigel invasion assays, the upper sides of membranes $(8 \mu \mathrm{m}$ pore Transwell, Fisher Scientific, Hampton, NH, USA) were pre-coated with a dilution of 1:25 Matrigel (BD Biosciences, Franklin Lakes, NJ, USA) and 10\% FBS-DMEM was added as a chemoattractant in the lower chamber. A number of $2.5 \times 10^{5} \mathrm{MyLa}$ and SeAx cells were plated in $150 \mu \mathrm{L}$ of SF-DMEM in the upper chamber. Following $48 \mathrm{~h}$ incubation, the invaded cells were fixed and analyzed by fluorescence microscopy and counted. Images were processed and analyzed using FIJI ImageJ 2.3.1 (NIH, Bethesda, MD, USA).

\subsection{D Tumour Spheroid Invasion Assay}

MyLa and SeAx cells $\left(4 \times 10^{3}\right.$ cells/well diluted in $\left.200 \mu \mathrm{L}\right)$ were seeded in lowadherence 96 well U-bottom plates (6055330, PerkinElmer, Waltham, MA, USA) and pelleted by centrifugation $(100 \times g$ for $5 \mathrm{~min})$. Two days after, tumor spheroid formation was visually confirmed, and the $3 \mathrm{D}$ invasion assay was performed. For that, $150 \mu \mathrm{L} /$ well of growth medium was removed from the spheroid plates and $50 \mu \mathrm{L}$ of BMM (356234, Corning, New York, NY, USA) was gently dispensed into the bottom well. To make sure the spheroids were in a central position, they were centrifuged $\left(300 \times g\right.$ for $3 \mathrm{~min}$ at $\left.4^{\circ} \mathrm{C}\right)$. Then, BMM was allowed to solidify for $1 \mathrm{~h}\left(37^{\circ} \mathrm{C}\right)$ and $100 \mu \mathrm{L} /$ well of complete growth medium including inhibitors ( $3 \times$ the desired final concentration) were added. Spheroids were monitored for 4 days by brightfield microscopy, imaging them each for $24 \mathrm{~h}$. Then, images were analyzed using QuPath1 to quantify spheroids' size and the number of invading cells.

\subsection{Immunohistochemistry}

After extraction, tissues were embedded in paraffin and cut using a microtome; $5 \mu \mathrm{m}$ sections were then placed on poly-L-lysine-treated slides. Before staining, slides were deparaffinized, and tissues were rehydrated. After that, the slides were dried $(1 \mathrm{~h}$ at $60^{\circ} \mathrm{C}$ or overnight at $37^{\circ} \mathrm{C}$ ). Then, permeabilization of cells was carried out by incubation (10 min) of tissues with $0.1 \%$ IGEPAL in $1 \times$ Tris Buffered Saline (TBS). After that, the specimens were washed $(2 \times, 5$ min with $1 \times$ TBS), and non-specific bindings were blocked using a serum-free blocking agent, background punisher (BIOCARE Medical, Pacheco, CA, USA), for $10 \mathrm{~min}$. Then, 1\% Bovine Serum Albumin (BSA) 0,1\% IGEPAL in 1× TBS solution with a primary mouse anti-rat CD44 antibody (diluted 1:100) (Antibodies Online, Aachen, Germany) or without primary antibody (negative control) was incubated overnight $\left(4^{\circ} \mathrm{C}\right)$. After incubation, specimens were washed in $1 \times$ TBS and incubated with $3 \times$ hydrogen peroxide in $1 \times$ TBS for 30 min to quench endogenous peroxidase. After that, the slides were 
washed again using $1 \times$ TBS and incubated $(1 \mathrm{~h})$ with a secondary anti-mouse biotinylated antibody (Vector Laboratories, Burlingame, CA, USA) (dilution 1:500 in 1\% BSA 0.1\% IGEPAL in $1 \times$ TBS). Then, slides were washed, as described above, and tissues were incubated (30 min) with horseradish peroxidase Avidin D (dilution 1:500 in 1× TBS). Finally, slides were washed again and incubated (5-10 $\mathrm{min}$ ) with diaminobenzidine (Gibco, Gaithersburg, MD, USA). In addition, tissues were stained with hematoxylin, dehydrated, cleared, and mounted with DPX. Micrographs were captured by a Zeiss Axio Scope A1 microscope (Carl Zeiss, Oberkochen, Germany).

\subsection{Western Blotting}

CAM tumors were lysed with RIPA buffer (Sigma Aldrich, Burlington, MA, USA), supplemented with phosphatase and protease inhibitors (Roche, Basel, Switzerland). Whole cell lysates were subjected to acrylamide SDS-PAGE using standard procedures, transferred onto a nitrocellulose support membrane (Amersham Protran, GE Healthcare Life Science, Marlborough, Mass, United States), and Western blotted. All primary and secondary antibodies were diluted 1:1000 and 1:5000 respectively, unless otherwise stated. The following antibodies were used: anti- $\alpha$-Tubulin (Santa Cruz Biotechnology, Dallas, TX, United States sc-23948), anti-phospho-ERK (Santa Cruz Biotechnology, sc-7383, RRID:AB_627545), anti-p44/42 MAPK (Erk1/2) (Cell Signaling Technology, Danvers, Mass, Unites States (137F5), Cat\# 4695, RRID:AB_390779), phospho p38 (Santa Cruz biotechnology, sc-166182), p38 (Santa Cruz Biotechnology, sc-728, RRID:AB_632140), phospho-AKT (Ser473) Antibody (Cell Signaling Technology, Cat\#9271), AKT Antibody (Cell Signaling Technology, Cat \#9272), p-Stat5A/B (Santa Cruz Biotechnology, (5G4), sc-81524), Stat5 (Santa Cruz Biotechnology, (A-9), sc-74442), and $\alpha$ Tubulin (Santa Cruz Biotechnology, DM1A, sc32293). Secondary antibodies: P/N 925-32212; RRID AB_2716622, P/N 925-32213; RRID AB_2715510, P/N 926-32213; RRID AB_621848. Signals were visualized and recorded with an Odyssey ${ }^{\circledR}$ M Imaging System LICOR (Lincoln, NE, USA).

\subsection{Statistical Analysis}

To evaluate results and statistical significance of control and experimental groups, we used Graph Pad Prism software and the Student's $t$-test or ANOVA analysis. Each global mean was compared using the two-tailed unpaired Student's $t$-test with a statistical significance of $p<0.05$ (95\% confidence interval). $p$ values: ${ }^{*}<0.05,{ }^{* *}<0.005,{ }^{* * *}<0.001$, $* * * *<0.0001$

\section{Results}

\subsection{Resminostat, Ruxolitinib, and Their Combination Inhibit Cell Proliferation and Induce Apoptosis in CTCL Cells}

We initially analyzed the cell viability and apoptotic effects of Ruxolitinib and/or Resminostat on MyLa and SeAx cells. It was shown that monotherapies decreased cell viability and enhanced apoptosis when compared to vehicle control without, however, reaching statistical significance (Figure 1A,B). On the other hand, the combination of the drugs significantly showed a $62 \%$ reduction in the viability of MyLa and 60\% reduction in SeAx cell lines $(p<0.001)$ when compared to controlled vehicle (Figure $1 \mathrm{~A}, \mathrm{~B})$. In addition, the drug combination enhanced apoptosis in MyLa by 2.85-fold and in SeAx cells by 3.7-fold when compared to untreated cells (MyLa, $p<0.005$; SeAx, $p<0.001$ ) (Figure 1C,D). 
A

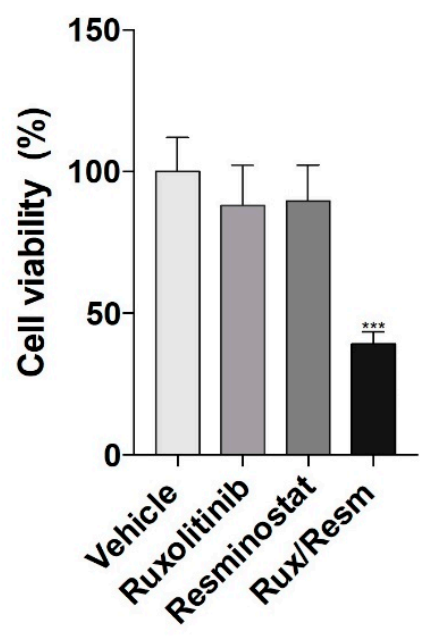

C

MyLa

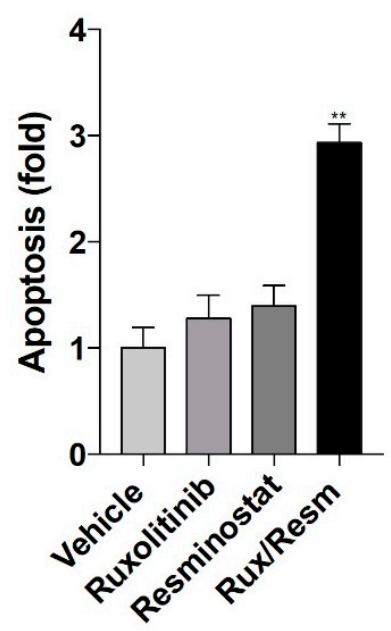

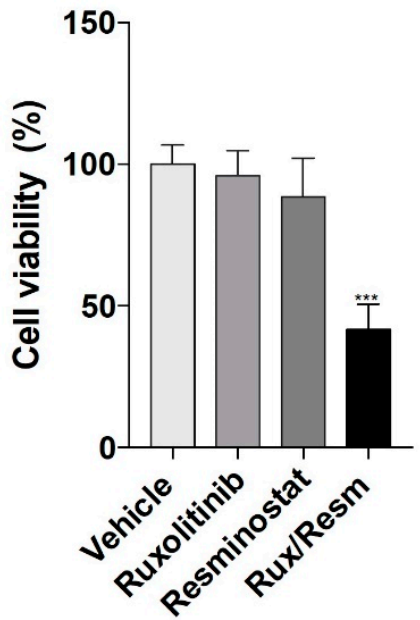

SeAx
D

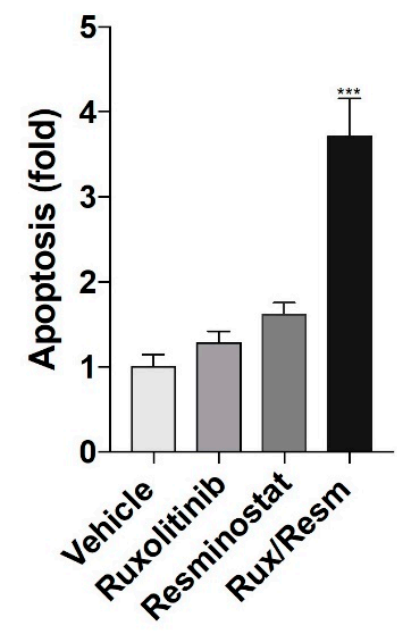

Figure 1. The effect of Resminostat, Ruxolitinib, and their combination in cell proliferation (A,B) and apoptosis (C,D) in CTCL cells. Cell proliferation was evaluated by AlamarBlue and apoptosis assay was performed by flow cytometry using FITC Annexin V. Data show mean \pm SEM from three $(n=3)$ independent experiments. $p$ values: ${ }^{* *}<0.005,{ }^{* * *}<0.001$.

\subsection{Combined Treatment of Resminostat and Ruxolitinib Impairs CTCL Tumorigenesis and Metastasis in Spontaneous Metastasis CAM Assay}

We proceeded to investigate the inhibitory effects of Resminostat and/or Ruxolitinib on tumorigenesis and metastasis, in the chick embryo spontaneous metastasis model. Upon inoculation with $10^{6}$ MyLa or SeAx cells onto their CAM, chick embryos developed large primary tumors (100-200 mg) within 7 days. The monotherapy inhibited primary tumor formation and CAM intravasation in both MyLa and SeAx embryos, but only in SeAx embryos was the reduction in tumor formation and CAM intravasation statistically significant when compared to vehicle $(p<0.005)$. On the other hand, the combination of Resminostat with Ruxolitinib was more effective in inhibiting the primary tumor formation (31\% in MyLa embryos, $p<0.01 ; 52 \%$ in SeAx embryos, $p<0.005$ ) (Figure 2A) and blocked CAM intravasation (82\% reduction in MyLa $(p<0.005)$ and $92 \%$ reduction in SeAx embryos $(p<0.005)$ ) (Figure 2B). Moreover, we detected that, in the control MyLa and SeAx embryos, 
neoplastic cells intravasated the distal CAM and disseminated to internal organs such as the lung and liver, forming secondary metastatic foci (Figure 2C,D). As far as the metastasis is concerned, it was demonstrated that the monotherapies blocked liver metastasis in both MyLa (Resminostat, $p<0.01$; Ruxolitinib, $p<0.005$ ) and SeAx embryos (Resminostat, $p<0.005)$.

A

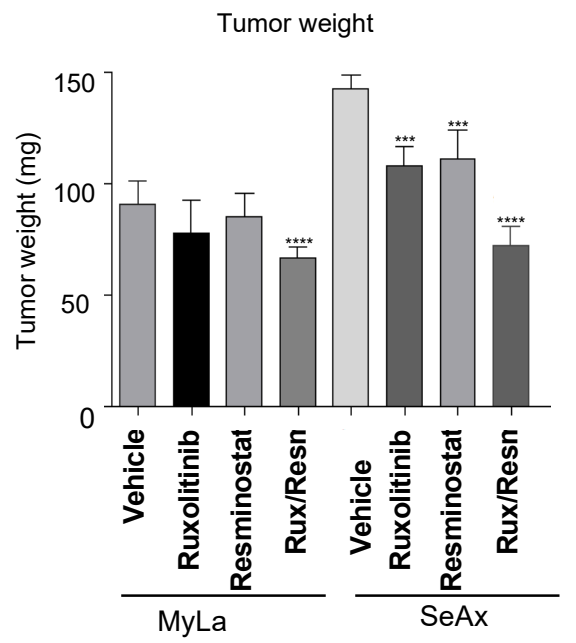

C

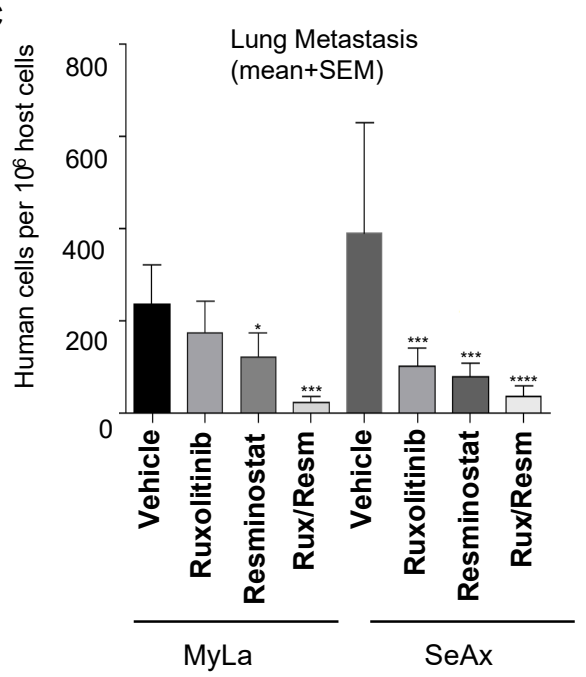

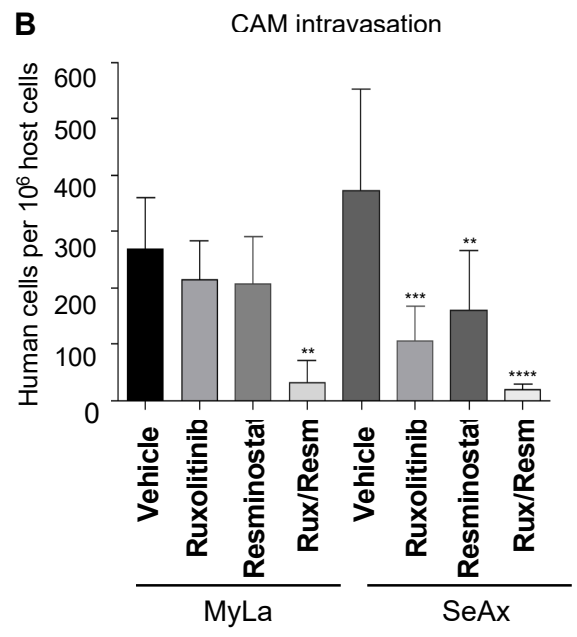

D

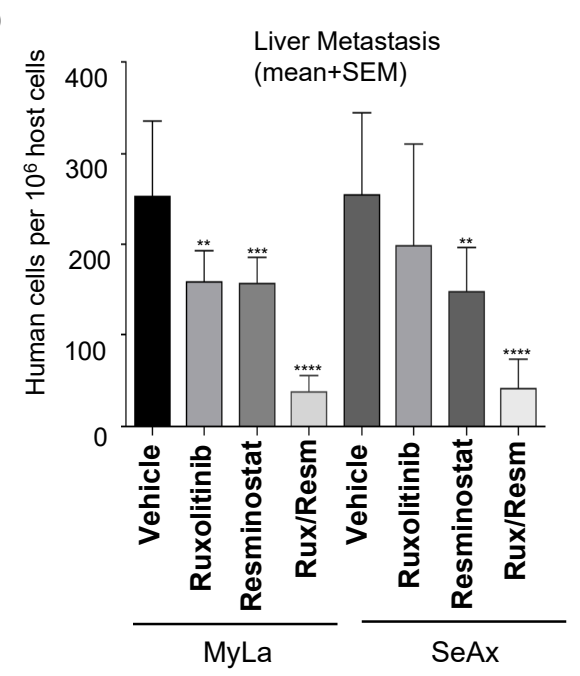

Figure 2. Evaluation of efficiency of Resminostat (Resm) and Ruxolitinib (Rux) to inhibit tumor growth (A), and metastatic spread of CTCL cells to chick chorioallantoic membrane (CAM) intravasation (B) and distant organs, lung and liver (C,D). CTCL cells were grafted onto the CAM of chick embryos $\left(1 \times 10^{6}\right.$ cells per embryo). Developing tumors were treated on days 2 and 4 with topical applications of corresponding agents. On day 7, the levels of tumor cell intravasation to the CAM (B) and metastasis to distant organs were quantified by Alu PCR. Primary tumors were excised and weighed to determine the effect of the treatments on tumor growth. Data show mean $\pm \mathrm{SEM}$ from three $(n=3)$ independent experiments, each employing from 14-18 embryos per treatment variant. $p$ values: ${ }^{*}<0.05,{ }^{* *}<0.005,{ }^{* * *}<0.001,{ }^{* * * *}<0.0001$. 
Lung metastasis was also blocked-in monotherapies (MyLa, Resminostat, $p<0.05$; SeAx, Resminostat $p<0.005$; Ruxolitinib, $p<0.005)$. As expected, the combination of drugs significantly blocked liver (76\% reduction in MyLa, $p<0.001 ; 75 \%$ reduction in SeAx, $p<0.005)$ and lung metastasis (87\% reduction in MyLa, $p<0.001 ; 79 \%$ reduction in SeAx, mboxemphp $<0.001)$.

To further demonstrate that the combination of Resminostat and Ruxolitinib impairs CTCL tumor formation, we performed an immunohistological analyses. We observed a formed primary tumor in CAM, and its margin can be demarcated as shown in Figure S1. In addition, we found that the combination of drugs significantly blocked intravasated CTCL cells in CAM blood vessels.

Then, we determined the synergistic effect between Resminostat and Ruxolitinib by the combination index (CI) as previously described [29]. The combination treatment exhibited synergistic effects in tumor growth and metastasis inhibition in both cell lines. In MyLa cells, CI was 0.782, whereas in SeAx cells, the CI was 0.741. These values indicate moderate synergism in tumor growth inhibition for both cell lines. For CAM intravasation, MyLa cells' CI was 0.194, whereas in SeAx cells, the CI was 0.213. For lung metastasis, MyLa cells' CI was 0.261, whereas in SeAx cells, the CI was 0.282. For liver metastasis, MyLa cells' CI was 0.279, whereas in SeAx cells, the CI was 0.295. These values indicate strong synergism in metastasis inhibition for both cell lines.

\subsection{Combined Treatment of Resminostat and Ruxolitinib Impairs CTCL Migration and Invasion}

Following the effect of Resminostat and Ruxolitinib in tumor formation and metastasis in vivo, we next investigated their effects on cell migratory and invasive potential. As it is shown in Figure 3, the migration trans-well assay was used, showing that monotherapies significantly reduced $(p<0.05)$ the migration of SeAx cells (Figure 3B,D). However, the combination of Resminostat with Ruxolitinb had a dramatic decrease in both cell lines when compared to untreated cells (MyLa-91\% reduction, $p<0.005$ : SeAx-92\% reduction, $p<0.005)$. On the contrary, in MyLa cells, only Resminostat resulted in a significant decrease $(p<0.05)$, as well as the combination therapy $(p<0.005)$, in migration. The invasion trans-well assay demonstrated that at $48 \mathrm{~h}$ post-treatment in MyLa cells, the combination of HDACi with JAKi was more effective $(p<0.005)$ than HDACi treatment alone $(p<0.05)$ (Figure $4 \mathrm{~A}, \mathrm{C})$. On the other hand, in SeAx cells, the combination of the drugs was more effective $(p<0.005)$ when compared to both monotherapies alone $(p<0.05)$ (Figure 4B,D). Additionally, a 3D tumor spheroid invasion assay showed that the combination of Resminostat with Ruxolitinb inhibited the invasive ability of MyLa $(p<0.005)$ and SeAx cells $(p<0.005)$ (Figure 5). Quantitative analysis indicated a 40-50\% reduction both in productive distance travelled by escaped CTCL cells and in the number of cells that had escaped from spheroids treated with Resminostat and Ruxolitinib.

\subsection{Combined Treatment of Resminostat and Ruxolitinib Reduce CTCL Extravasation CAM Assay}

We next validated the effect of combined treatment of Resminostat and Ruxolitinib during metastatic dissemination of CTCL cells. For this purpose, we analyzed the invasive ability of CTCL cells and the colonization behavior of MyLa and SeAx using the experimental metastasis model in chick embryo. The 3D invasion assay showed that the combined treatment inhibited the invasive ability of CTCL cells (MyLa-49\% reduction distance, $p<0.005$; SeAx $-36 \%$ reduction in distance, $p<0.005$ ) (Figure 5). 
A
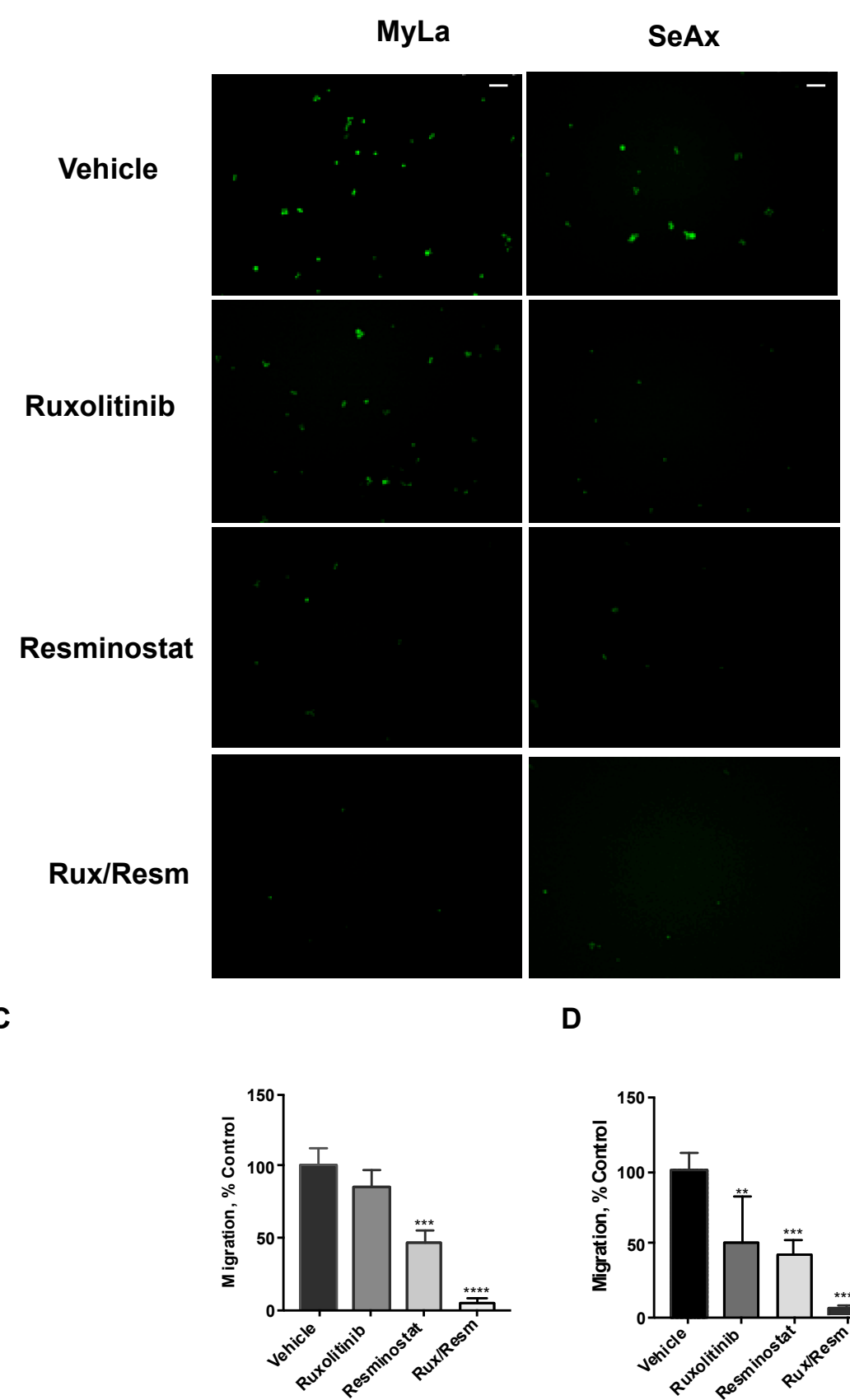

B

D

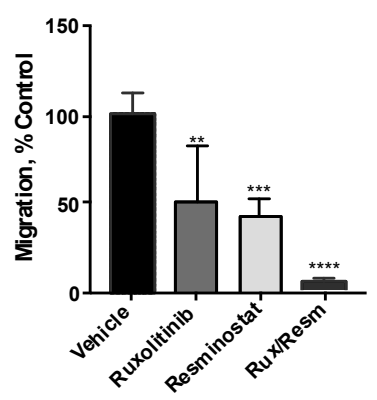

Figure 3. The inhibitory effect of combined treatment of Resminostat and Ruxolitinib in CTCL transwell migration. Fluorescent-labeled cells were placed into trans-well inserts. Tumor cells that crossed the pores' membrane were quantified after $16 \mathrm{~h}$. Representative pictures of migration assay using Myla (A) and SeAx (B) cells treated as indicated. Quantification of invasion of Myla (C) and SeAx (D) cells. Scale bar, $100 \mu \mathrm{m}$. Images from a representative experiment out of three independent experiments were performed in triplicate. Data are mean \pm SEM. $p$ values: ${ }^{* *}<0.005,{ }^{* * *}<0.001$, $* * * * 0.0001$. 
A

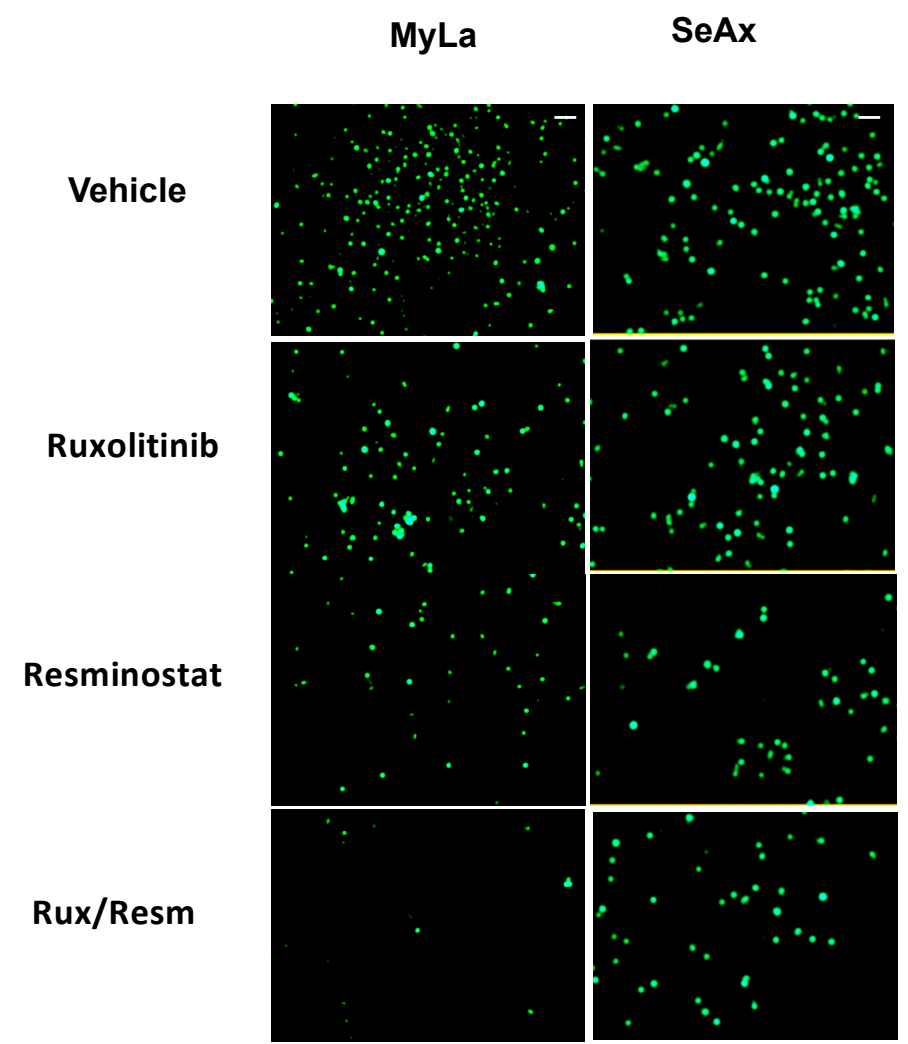

C

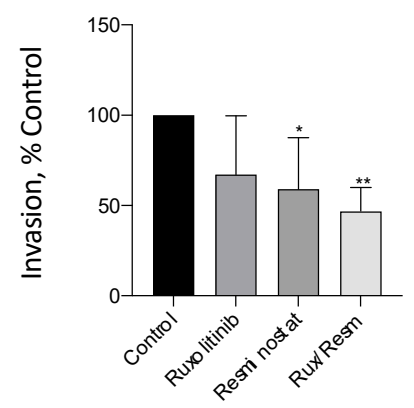

B

\section{$\operatorname{SeAx}$}

D

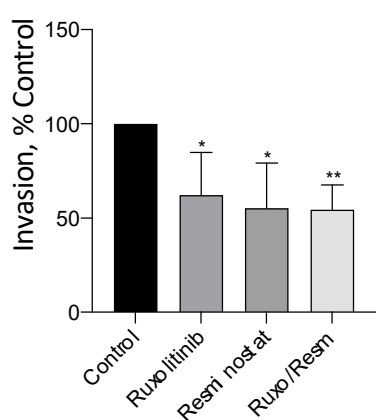

Figure 4. The inhibitory effect of combined treatment of Resminostat and Ruxolitinib in CTCL transwell invasion assay. Fluorescent-labeled cells were placed into Matrigel-covered inserts. Tumor cells that crossed Matrigel and pores of the membrane were analyzed after $48 \mathrm{~h}$ by fluorescent microscopy. Representative pictures of transwell invasion assay using Myla (A) and SeAx (B) cells treated as indicated. Quantification of invasion of Myla (C) and SeAx (D) cells. Scale bar, $100 \mu \mathrm{m}$ (Data show mean \pm SEM from three $(n=3)$ independent experiments performed in triplicate. $p$ values: ${ }^{*}<0.05,{ }^{* *}<0.005$. 
A

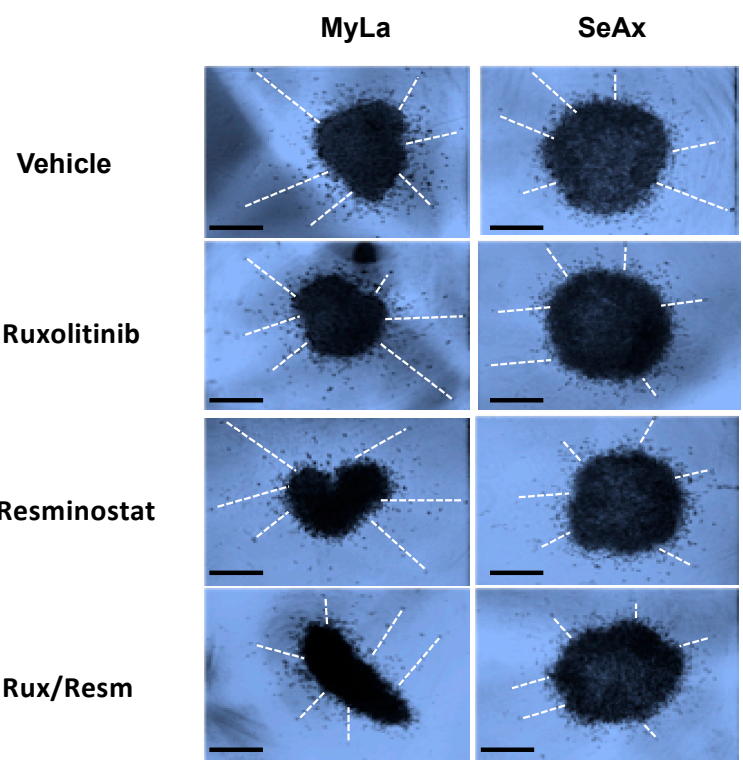

C

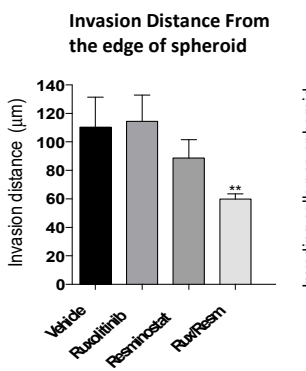

MyLa

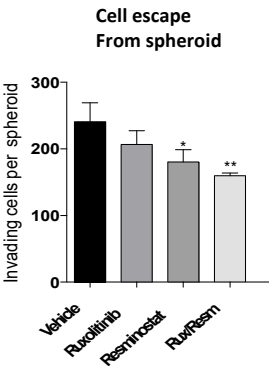

D

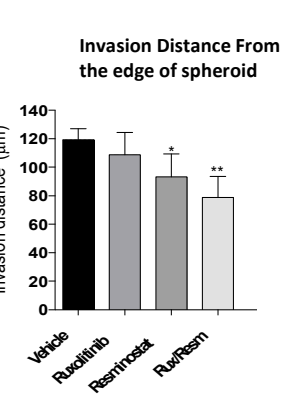

SeAx

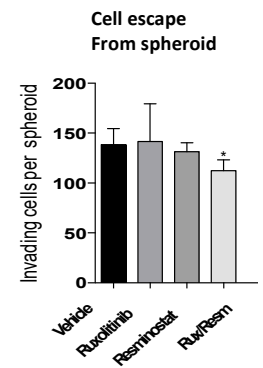

Figure 5. 3D tumor spheroid invasion assay to determine the efficiency of the combination of Resminostat with Ruxolitinib. Representative pictures of Myla (A) and SeAx (B) 3D spheroids after $48 \mathrm{~h}$. The combined therapy inhibited the invasive ability of CTCL cells. Representative images of CTCL spheroids showing cell escape and invasion. (C,D) Quantification of spheroid cell escape and invasion. Mean invasion distance covered by escaped cells from the edge of the spheroid and (left graphs) and the number of cells escaped from the spheroid (right graphs) were determined in acquired images after $48 \mathrm{~h}$. Images from a representative experiment and data show mean \pm SEM from three $(n=3)$ independent experiments performed in triplicate. Scale bar: $50 \mu \mathrm{m} p$ values: $*<0.05, * * 0.005$.

Interestingly, by day 5, the combination of Resminostat and Ruxolitinib produced a significant decrease in the number of human tumor cells detected in the CAM (MyLa$72 \%$ reduction, $p<0.005$; SeAx-79\%, $p<0.005)$, liver (MyLa-78\% reduction, $p<0.005$; SeAx-92\% reduction, $p<0.001$ ), and lung (MyLa-68\% reduction, $p<0.005 ;$ SeAx-89\% reduction, $p<0.001)$. Under these in vivo conditions, combined treatment reduced the colonization capability of CTCL cells (Figure 6). Then, we analyzed the colonization behavior of Myla and SeAx cells by live-cell imaging of fluorescently labeled tumor cells in the CAM tissue. Twenty-four hours after cell inoculations, control MyLa and SeAx cells appeared to extravasate normally from the terminal CAM capillaries. In contrast, the combination of Resminostat with Ruxolitinb dramatically decreased the number of extravasated cells (Figure 6D). 
A

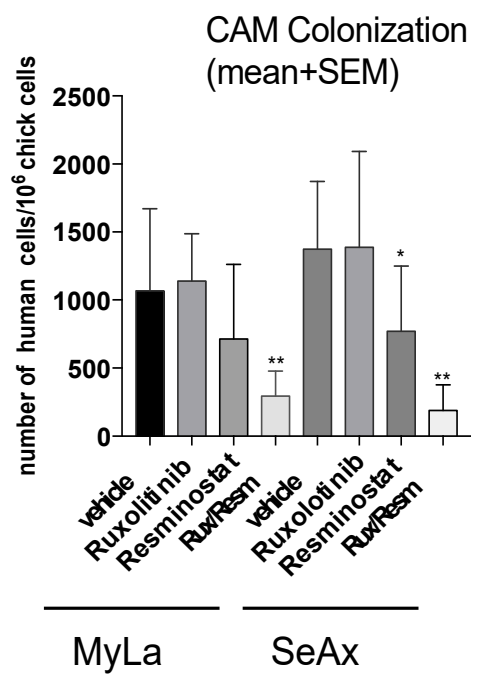

C

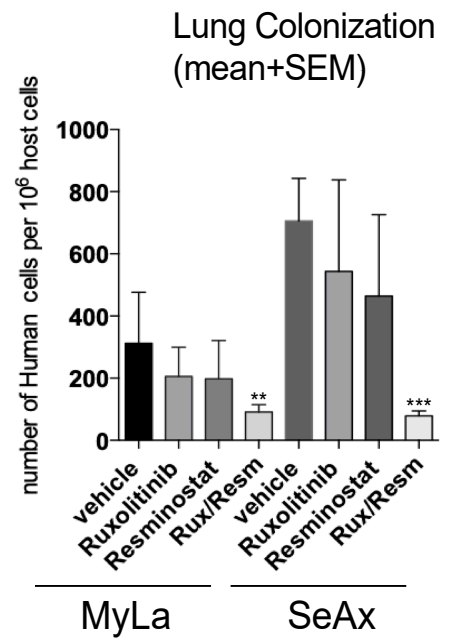

B

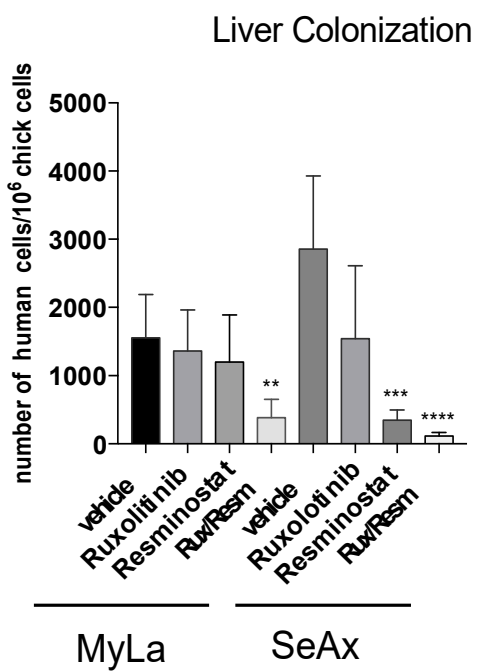

D

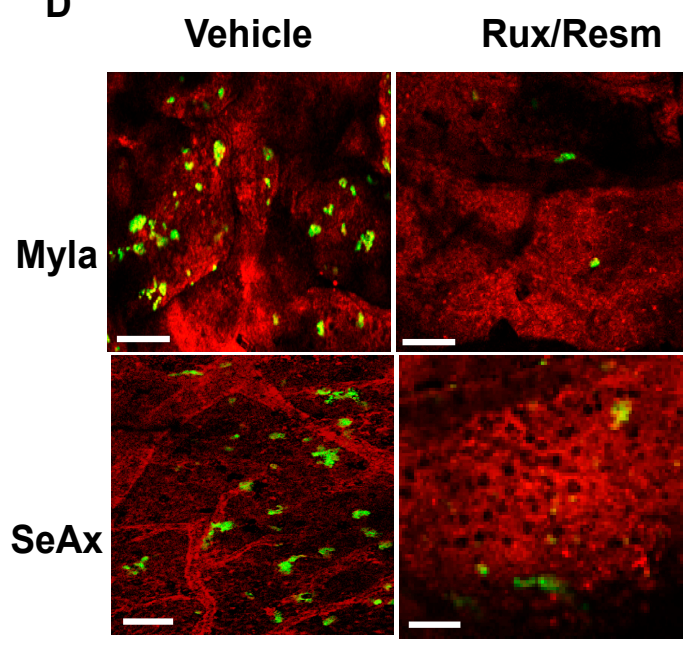

Figure 6. The effect of Resminostat and Ruxolitinib during colonization of CTCL cells in an experimental metastasis model in chick embryo. The combination of Resminostat and Ruxolitinib produced a significant decrease in the number of human tumor cells detected in CAM (A), liver (B), and lung (C). Chick embryos were injected with Myla or SeAx cells. At day 5, the levels of colonization in organs were analyzed by Alu PCR. The bars are the means determined in three $(n=3)$ independent experiments using from 12-16 embryos per variant. $p$ values: ${ }^{*}<0.05,{ }^{* *}<0.005,{ }^{* * *}<0.001,{ }^{* * * *}<0.0001$. (D). The colonization behavior of MyLa and SeAx cells by live-cell imaging of fluorescently labeled tumor cells in the CAM tissue. Live image analysis of CTCL cells was performed $24 \mathrm{~h}$ after green fluorescent-labeled cells were inoculated into chick embryos, vasculature was highlighted with red fluorescent Rhodamine. Scale bar: $50 \mu \mathrm{m}$.

3.5. Resminostat, Ruxolitinib, and Their Combination Inhibit Key Signaling Pathways in CTCL Xenografted Tumors

To further investigate the signal transduction pathways that are activated by single or combinational Resminostat and Ruxolitinib treatment, we performed Western blot analyses in CAM tumors for several key implicated molecules. We investigated the expression of total p38 with the phosphorylated p-p38 (Tyr182), the total AKT protein with the phosphorylated p-AKT (Ser473), the total protein ERK with the phosphorylated p-ERK (Tyr204), as well as the total STAT5 with the phosphorylated p-STAT5 (Tyr694/699). Normalization 
of protein levels was achieved using the expression levels of $\alpha$-tubulin. As is depicted on Figure 7 (Figures S2-S4), in MyLa cells, the monotherapies resulted in a significant decrease only in the phosphorylation of p-AKT $(p<0.005)$. In contrast, the combination of Resminostat with Ruxolitinib inhibited the phosphorylation of $\mathrm{p}-\mathrm{p} 38$ by $58 \%(p<0.001)$, p-AKT by $64 \%(p<0.0001)$, p-ERK by $83 \%(p<0.0001)$, and p-STAT5 by $45 \%(p<0.005)$. In SeAx cells, the monotherapies showed a significant inhibition in the phosphorylation of p-ERK $(p<0.005)$, whereas the combinational treatment was more effective in the reduction of the phosphorylation of p-p38 by $35 \%(p<0.005)$, p-AKT by $37 \%(p<0.05)$, p-ERK by $93 \%$ $(p<0.0001)$, and $\mathrm{p}-\mathrm{STAT} 5$ by $30 \%(p<0.005)$.

MyLa

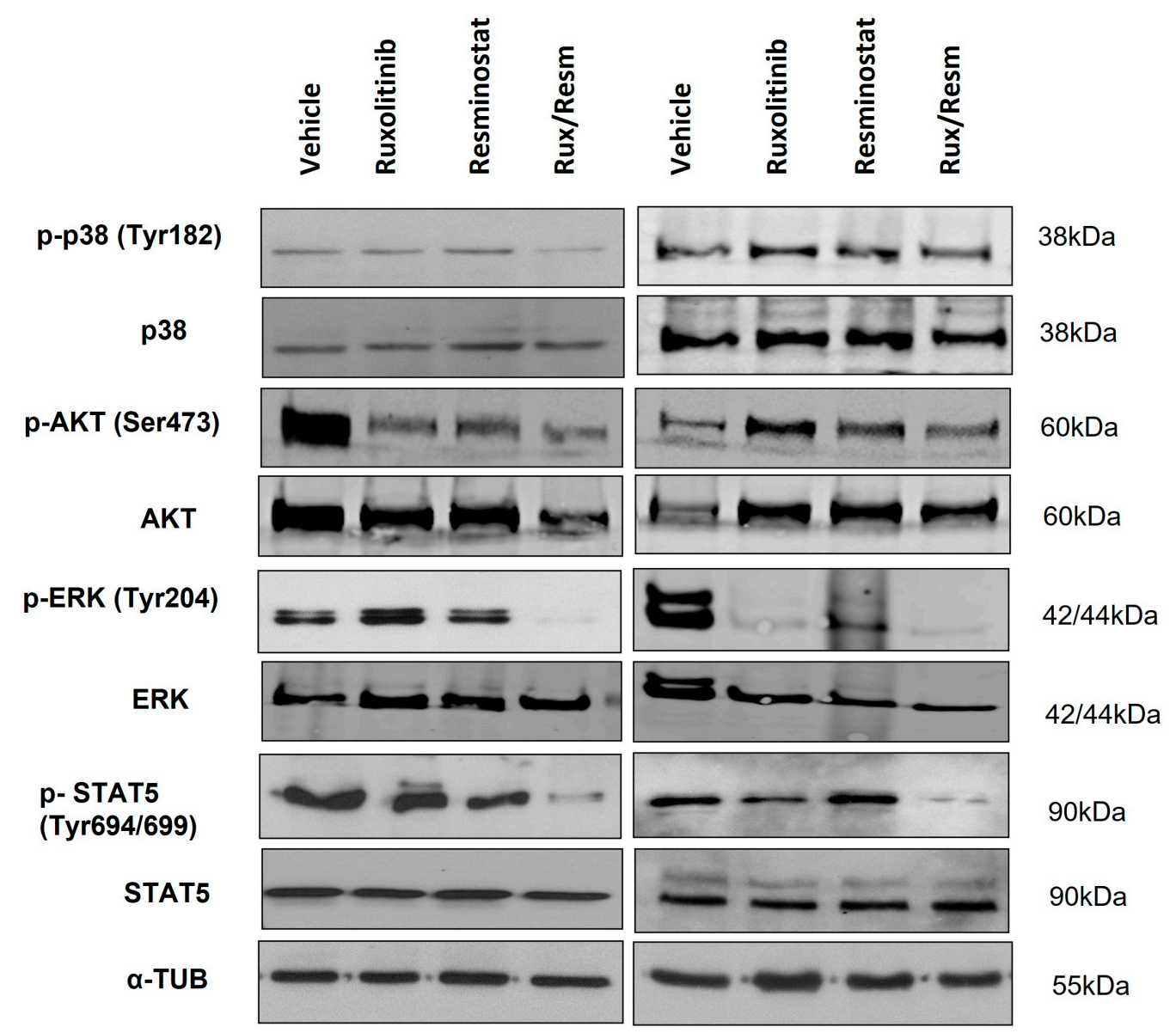

\section{SeAx}

Figure 7. Western blot analyses in CTCL CAM tumors for key implicated pathways. Portions of primary tumors were lysed and analyzed for the activation levels of p-38 (Tyr1 82), p-AKT (Ser473), p-ERK (Tyr 204), p-STAT5 (Tyr694/699), and $\alpha$-tubulin. Uncropped full western blot figures are included as Supplementary Materials (Figure S3).

\section{Discussion}

Currently, MF/SS are incurable diseases with a dismal prognosis in advanced stages and urgent requirement of more effective treatment. The selection of therapy is mainly based on disease stage. Though more effective treatments are available for early-stage disease, late-stage disease treatments remain largely ineffective [30]. In selected MF/SS cases, stem cell transplantation presents the only treatment option [31,32]. Brentuximab and Mogalizumab are 'milestone' additions to CTCL therapy. Combinational treatments produce higher complete response rates, however disease-free survival and overall survival do not differ from sequential conservative therapy [33-42]. New or repurposed drugs 
for CTCL need to be tested in a well-established, functional, and reproducible in vivo model. However, a representative in vivo CTCL model is currently lacking to study the development and progression of MF/SS, and is highly demanded for the validation of in vitro results and detection of promising therapeutics that may lead to clinical trials. The present study aimed to establish an in vivo model for MF/SS, characterized by rapid tumor growth after transplantation of an unselected 'primary' malignant $\mathrm{T}$ cell line, with a high, robust, and predictable tumor take, and finally, the creation of macroscopically visible secondary tumors. To the best of our knowledge, this is the first study that developed and employed an MF/SS chicken CAM model for the evaluation of new combinational treatment options in CTCL in vivo.

Although a few preclinical in vivo CTCL models have been previously developed, they present several problems, mainly attributed to the small availability of CTCL cell lines, which are derived from blood samples of patients with CTCL, the difficulties to grow them in vitro [43-45], and the inability to obtain tumor metastasis macroscopically [46]. Current animal models of CTCL include transplantation of human skin grafts into mice with severe combined immune insufficiency (SCID), or subcutaneous transplantation of MyLa cells to the flanks of athymic nude mice lacking $\mathrm{T}$ cells and T cell-dependent antibody responses, to generate an alternative mouse xenograft model. Although a subcutaneous site improves tumor growth monitoring, it is neither a physiological nor an optimal environment for CTCL cell line expansion. In fact, most studies in immunodeficient mice involving subcutaneous injection of fresh cells from patients or CTCL cell lines have failed. In addition, CTCL cells may need an appropriate homing site delivering the necessary growth factors, and, thus, studies have considered the intrahepatic mouse route as interesting for CTCL, in which malignant $\mathrm{T}$ cells often circulate [47]. A mouse model for both aggressive and indolent CTCL cell line engraftment has been established to evaluate differences in CTCL tumorigenicity, migration, and spreading capacities, but further studies are needed to evaluate its functionality and reproducibility [48].

Unlike mouse models that have been previously employed in CTCL research, the chick embryo CAM assay (in ovo and ex ovo) is a simple, easy, and fast in vivo model where microtumors appear in 2 to 5 days after tumor cell transplantation, compared to 3 to 6 weeks in mammalian models. The benefits of the CAM assay include easy monitoring of the tumor extravasation and intravasation into the microvasculature and consequent formation of metastases in organs, evaluated by qPCR $[49,50]$. Regarding drug testing, most research has used the CAM assay to investigate the antiangiogenic or angiogenic potential of compounds/materials and their impact on embryo development [51,52]. The CAM assay can be used to study the activity of candidate molecules (new or repurposed) for anticancer therapy in vivo without the need for a rodent facility or ethical approvals for animal experimentation, since the CAM is not innervated, and tests are not connected with pain perception by the embryo. Current animal experimentation legislation in the European Union and Switzerland enable testing with chick embryos without the approval of animal experimentation committees.

Taking into account the tremendous advantages of the chick embryo CAM model, we proceeded to expand our previous in vitro effects of Resminostat and Ruxolitinib combination in vivo [20].

HDAC inhibitors are a promising class of therapeutic agents for a wide range of cancers $[53,54]$. It is known that HDAC inhibitors that are currently in use for CTCL are Vorinostat (FDA approved, 2006) and Romidepsin (FDA approved, 2009). On the other hand, Resminostat is under approval, since it is running the pivotal European RESMAIN study, aiming for the evaluation of Resminostat in maintenance treatment of patients with advanced stage (Stage IIB-IVB) MF/SS that have achieved disease control with systemic therapy. Despite the approval by the FDA for the treatment of certain cancers, HDACi have been shown to have a limited therapeutic efficacy against solid tumors as a single therapeutic agent. HDAC inhibitors reduce JAK-2 expression, likely due to effects on JAK-2 mRNA expression and through increased JAK-2 proteasomal deterioration [55-57]. The 
curative potential of JAK inhibitors appears to be limited, and the survival benefits are controversial with limited follow-up available [58]. However, HDACi have been shown to function synergistically with a range of structurally and functionally diverse chemical compounds, biologically active polypeptides, and novel immune therapies. Combining HDACi with other cancer therapeutics may thus be an avenue to achieve their full therapeutic potential [59-62].

Ruxolitinib is an oral JAK1/2 inhibitor, recently FDA-approved for treatment use in myelofibrosis and polycythemia Vera. It is also indicated for the treatment of various solid tumors (breast, pancreatic, colorectal, head and neck, and prostate) and hematologic illnesses (CLL, ALL, AML, CML, and NSCLC). Findings from pooled 5-year data from COMFORT trials [63] demonstrated long-term OS benefit from Ruxolitinib, but Ruxolitinib resistance also develops following chronic drug exposure [64], highlighting a clear need for combined therapies; it would be advantageous to conduct a clinical trial in the near future to overcome the resistance and toxicity of monotherapy in CTCL patients. Combination therapy might prove beneficial due to synergistic impacts on oncogenic transformation, which can enable the effective use of lower doses of the different agents with better tolerability, and might avoid or delay the development of drug resistance, as is shown in other hematological malignancies.

The combination of Resminostat, an HDACi, with Ruxolitinib, a JAKi exhibiting synergistic antitumor effects, resulted in the blockade of metastasis and inhibition of key molecules in implicated signaling pathways in the chick embryo xenograft model of CTCL. We observed that a single administration of Resminostat or Ruxolitinib inhibited cell viability and induced apoptosis of both CTCL cell lines.

Monotherapies decreased tumor formation and blocked CAM intravasation in spontaneous metastasis assay, but only in SeAx cells was the change statistically significant, indicating a differential response of SS from MF. As far as the effect of monotherapies in migration and invasion were concerned, we demonstrated that in MyLa cells, only the Resminostat significantly decreased migration and invasion, whereas in SeAx cells, both monotherapies were effective. This finding further demonstrates that different mechanisms are implicated during CTCL progression. These differences could be explained by the heterogeneity in cell origin and CTCL subtype between MF and SS.

Interestingly, the drug combination was most effective in inhibiting cell proliferation, inducing apoptosis, decreasing tumor formation, and blocking CAM intravasation. These altered cellular functions were mainly attributed to the drug synergy which induced a strong inhibition of key signaling pathways such as AKT, MAPK, and JAK/STAT. It has been shown that Ruxolitinib inhibits cell proliferation, STAT activation, and DNA synthesis, while activating apoptosis in CTCL cell lines [20,65,66]. On the other hand, Resminostat has been shown to restrain the phosphorylation of 4EBP1 and p70S6K, indicating a deregulation in AKT signaling [67]. Treatment of CTCL cell lines with Resminostat was demonstrated to reduce Bim and Bax protein levels along with Bcl-xL [67]. The study of Yumeen et al. (2020) supported the clinical implementation of Ruxolitinib as a novel therapy for leukemic CTCL and further enforced the synergistic potential combination of Ruxolitinib with BCL2, HDAC, BET, or proteasome inhibition [68]. On the other hand, HDAC inhibitors were shown to reduce JAK-2 expression, possibly due to effects on JAK-2 mRNA expression and through increased JAK-2 proteasomal deterioration [66]. Particularly, Vorinostat, another HDACi, and Ruxolitinib together enhanced STAT5 dephosphorylation, inhibiting its pathway [66]. Civallero et al. demonstrated that the combination of Ruxolitinib with Vorinostat in CTCL could affect cell proliferation by targeting the glycolytic and oxidative pathways [66].

In order to further elucidate the mechanism of action of the proposed synergistic treatment, additional functional investigation is required to elucidate the underlying mechanism of action since it is a multifactorial event which is determined by the extensive crosstalk between the different signal transduction pathways implicated in CTCL. When the effect of Resminostat or Ruxolitinib was investigated on CAM tumors, those arisen by 
MyLa cells showed a significant decrease in the phosphorylation of AKT when compared to the untreated CAM tumors. On the contrary, CAM tumors arisen by SeAx cells showed a dramatic inhibition in the phosphorylation of ERK when treated with either Resminostat or Ruxolitinib. We have previously shown that activation of the AKT/mTOR pathway in MF is correlated with NOTCH1, p-ERK, and p-STAT3, and is implicated in the acquisition of a more aggressive phenotype. Moreover, the combination of p-AKT, p-p70S6K, and p-4E-BP1 emerged as a significant potential prognostic marker in patients with advanced disease stage $[69,70]$. Drug combination also blocked the signaling of p-p38, p-AKT, p-ERK, and p-STAT in MyLa cells, and p-ERK and p-STAT in SeAx cells. This could be attributed to the drug synergy that we showed from the combination of Resminostat with Ruxolitinib. On the contrary, our in vitro data previously demonstrated that the Resminostat/Ruxolitinib drug combination affected the activation of AKT in both cell lines, whereas it also inhibited JAK/STAT and MAPK activation in the MF cell line. This finding further indicates the differential genetic and epigenetic mechanisms implicated in MF and SS, as well as the differences in signaling pathways in vitro and in vivo, since malignant $\mathrm{T}$ cells present variations in the activation of cellular signaling due to extensive crosstalk between different signal transduction pathways.

Our results revealed that the two drugs exhibit differential profiles of inhibition in terms of key signaling molecule activation in the CTCL cell lines tested both in vitro [18], as well as in the present study in vivo, further confirming that MF and SS should be considered as different diseases, arising from distinct $T$ cell subsets [71-73]

Combination therapy of Resminostat and Ruxolitinib might prove beneficial for CTCL patients due to the synergistic impacts on basic cellular functions and on the inhibitory effect on key signaling molecules. This synergistic treatment could enable the effective use of lower doses of the different agents with better tolerability and might avoid or delay the development of drug resistance.

\section{Conclusions-Future Directions}

Our findings, using the chick embryo CAM spontaneous metastasis model, indicated that the JAKi/HDACi combination exhibited synergistic antitumoral effects and blocked CAM intravasation, as well as liver and lung metastasis, while it inhibited migration and invasion. The proposed drug combination also inhibited key signaling molecules, highlighting the significance of these pathways in the CTCL development and progression. Therefore, it may represent a promising novel therapeutic modality for CTCL patients. Importantly, the in vivo chick CAM metastasis model could be a good CTCL pre-clinical model to discover new treatments and further improve CTCL patients' survival, who fail to benefit from monotherapy.

Supplementary Materials: The following supporting information can be downloaded at: https: / / www.mdpi.com/article/10.3390/cancers14041070/s1, Figure S1: Determination of efficiency of Resminostat (Resm) and Ruxolitinib (Rux) to inhibit growth of CTCL xenograft; Figure S2: Quantification of Western Blot analyses in CAM tumors; Figure S3: Unprocessed images for Western blot results corresponding to the Figure 7; Figure S4: Densitometry data generated for Western blot results corresponding to the Figure 7 using Image J.

Author Contributions: Conceptualization, C.P., B.C., V.P. and E.P.; Data curation, C.P., B.C. and E.P.; Formal analysis, C.P., B.C. and K.L.; Investigation, F.K., K.L., V.P. and E.P.; Methodology, B.C., D.d.l.F.-V. and R.G.-G.; Project administration, E.P.; Resources, B.C.; Supervision, B.C. and E.P.; Writing—original draft, F.K.; Writing—review \& editing, F.K., C.P., B.C., K.L. and E.P. All authors have read and agreed to the published version of the manuscript.

Funding: This research was funded by a PIE grant (PIE-202020E007) at B.C lab from Consejo Superior de Investigaciones Científicas (CSIC)-MCIU, the Ramon y Cajal Research Program (MCIU, RYC2018-024004-I) and a LA FUNDACIÓ D’ESTUDIS I RECERCA ONCOLÒGICA (FERO) grant (BFERO2021.03).

Institutional Review Board Statement: Not applicable. 
Informed Consent Statement: Not applicable.

Data Availability Statement: The data presented in this study are available in this article (and Supplementary Material).

Conflicts of Interest: The authors declare no conflict of interest.

\section{References}

1. Willemze, R.; Jaffe, E.S.; Burg, G.; Cerroni, L.; Berti, E.; Swerdlow, S.H.; Ralfkiaer, E.; Chimenti, S.; Diaz-Perez, J.L.; Duncan, L.M.; et al. WHO-EORTC Classification for Cutaneous Lymphomas. Blood 2005, 105, 3768-3785. [CrossRef]

2. Girardi, M.; Heald, P.W.; Wilson, L.D. The Pathogenesis of Mycosis Fungoides. N. Engl. J. Med. 2004, 350, 1978-1988. [CrossRef] [PubMed]

3. Querfeld, C.; Guitart, J.; Kuzel, T.M.; Rosen, S.T. Primary Cutaneous Lymphomas: A Review with Current Treatment Options. Blood Rev. 2003, 17, 131-142. [CrossRef]

4. Willemze, R.; Cerroni, L.; Kempf, W.; Berti, E.; Facchetti, F.; Swerdlow, S.H.; Jaffe, E.S. The 2018 Update of the WHO-EORTC Classification for Primary Cutaneous Lymphomas. Blood 2019, 133, 1703-1714. [CrossRef]

5. Arulogun, S.O.; Prince, H.M.; Ng, J.; Lade, S.; Ryan, G.F.; Blewitt, O.; McCormack, C. Long-Term Outcomes of Patients with Advanced-Stage Cutaneous T-Cell Lymphoma and Large Cell Transformation. Blood 2008, 112, 3082-3087. [CrossRef]

6. Pavlidis, A.; Piperi, C.; Papadavid, E. Novel Therapeutic Approaches for Cutaneous T Cell Lymphomas. Expert Rev. Clin. Immunol. 2021, 17, 629-641. [CrossRef] [PubMed]

7. Khan, S.; Sawas, A. Antibody-Directed Therapies: Toward a Durable and Tolerable Treatment Platform for CTCL. Front. Oncol. 2019, 9, 645. [CrossRef] [PubMed]

8. Oka, T.; Miyagaki, T. Novel and Future Therapeutic Drugs for Advanced Mycosis Fungoides and Sézary Syndrome. Front. Med. 2019, 6, 116. [CrossRef]

9. Samimi, S.; Morrissey, K.; Anshelevich, S.; Evans, K.; Gardner, J.; Musiek, A.; Vittorio, C.; Rook, A.; Kim, E. Romidepsin and Interferon Gamma: A Novel Combination for Refractory Cutaneous T-Cell Lymphoma. J. Am. Acad. Dermatol. 2013, 68, e5. [CrossRef]

10. Kim, S.R.; Lewis, J.M.; Cyrenne, B.M.; Monico, P.F.; Mirza, F.N.; Carlson, K.R.; Foss, F.M.; Girardi, M. BET Inhibition in Advanced Cutaneous T Cell Lymphoma Is Synergistically Potentiated by BCL2 Inhibition or HDAC Inhibition. Oncotarget 2018, 9, 29193-29207. [CrossRef]

11. Froehlich, T.C.; Müller-Decker, K.; Braun, J.D.; Albrecht, T.; Schroeder, A.; Gülow, K.; Goerdt, S.; Krammer, P.H.; Nicolay, J.P. Combined Inhibition of Bcl-2 and NFkB Synergistically Induces Cell Death in Cutaneous T-Cell Lymphoma. Blood 2019, 134, 445-455. [CrossRef] [PubMed]

12. Zhao, L.; Okhovat, J.P.; Hong, E.K.; Kim, Y.H.; Wood, G.S. Preclinical Studies Support Combined Inhibition of BET Family Proteins and Histone Deacetylases as Epigenetic Therapy for Cutaneous T-Cell Lymphoma. Neoplasia 2019, 21, 82-92. [CrossRef] [PubMed]

13. Vu, K.; Wu, C.H.; Yang, C.Y.; Zhan, A.; Cavallone, E.; Berry, W.; Heeter, P.; Pincus, L.; Wieduwilt, M.J.; William, B.M.; et al. Romidepsin Plus Liposomal Doxorubicin Is Safe and Effective in Patients with Relapsed or Refractory T-Cell Lymphoma: Results of a Phase I Dose-Escalation Study. Clin. Cancer Res. Off. J. Am. Assoc. Cancer Res. 2020, 26, 1000-1008. [CrossRef] [PubMed]

14. Phyo, Z.H.; Shanbhag, S.; Rozati, S. Update on Biology of Cutaneous T-Cell Lymphoma. Front. Oncol. 2020, 10, 765. [CrossRef] [PubMed]

15. Dulmage, B.O.; Geskin, L.J. Lessons Learned from Gene Expression Profiling of Cutaneous T-Cell Lymphoma. Br. J. Dermatol. 2013, 169, 1188-1197. [CrossRef] [PubMed]

16. Koboldt, D.C.; Steinberg, K.M.; Larson, D.E.; Wilson, R.K.; Mardis, E.R. The Next-Generation Sequencing Revolution and Its Impact on Genomics. Cell 2013, 155, 27. [CrossRef]

17. van Doorn, R.; van Kester, M.S.; Dijkman, R.; Vermeer, M.H.; Mulder, A.A.; Szuhai, K.; Knijnenburg, J.; Boer, J.M.; Willemze, R.; Tensen, C.P. Oncogenomic Analysis of Mycosis Fungoides Reveals Major Differences with Sezary Syndrome. Blood 2009, 113, 127-136. [CrossRef]

18. Meyer, S.C.; Keller, M.D.; Chiu, S.; Koppikar, P.; Guryanova, O.A.; Rapaport, F.; Xu, K.; Manova, K.; Pankov, D.; O’Reilly, R.J.; et al. CHZ868, a Type II JAK2 Inhibitor, Reverses Type I JAK Inhibitor Persistence and Demonstrates Efficacy in Myeloproliferative Neoplasms. Cancer Cell 2015, 28, 15-28. [CrossRef]

19. Mullally, A.; Ebert, B.L. Janus Reveals Another Face: The Biologic Rationale for Targeting Janus Kinase 2 in Lymphoma. J. Clin. Oncol. Off. J. Am. Soc. Clin. Oncol. 2012, 30, 4168-4170. [CrossRef]

20. Karagianni, F.; Piperi, C.; Mpakou, V.; Spathis, A.; Foukas, P.G.; Dalamaga, M.; Pappa, V.; Papadavid, E. Ruxolitinib with Resminostat Exert Synergistic Antitumor Effects in Cutaneous T-Cell Lymphoma. PLoS ONE 2021, 16, e0248298. [CrossRef]

21. Merlos Rodrigo, M.A.; Casar, B.; Michalkova, H.; Jimenez Jimenez, A.M.; Heger, Z.; Adam, V. Extending the Applicability of In Ovo and Ex Ovo Chicken Chorioallantoic Membrane Assays to Study Cytostatic Activity in Neuroblastoma Cells. Front. Oncol. 2021, 11. [CrossRef] [PubMed]

22. Crespo, P.; Casar, B. The Chick Embryo Chorioallantoic Membrane as an in Vivo Model to Study Metastasis. BIO-PROTOCOL 2016, 6, e1962. [CrossRef] 
23. Fonseca, B.B.; da Silva, M.V.; de Morais Ribeiro, L.N. The Chicken Embryo as an in Vivo Experimental Model for Drug Testing: Advantages and Limitations. Lab Anim. 2021, 50, 138-139. [CrossRef] [PubMed]

24. Weber, W.T.; Mausner, R. Migration Patterns of Avian Embryonic Bone Marrow Cells and Their Differentiation to Functional T and B Cells. Adv. Exp. Med. Biol. 1977, 88, 47-59. [CrossRef] [PubMed]

25. Janković, B.D.; Isaković, K.; Lukić, M.L.; Vujanović, N.L.; Petrović, S.; Marković, B.M. Immunological capacity of the chicken embryo. I. Relationship between the maturation of lymphoid tissues and the occurrence of cell-mediated immunity in the developing chicken embryo. Immunology 1975, 29, 497. [PubMed]

26. Marga Janse, E.; Jeurissen, S.H.M. Ontogeny and Function of Two Non-Lymphoid Cell Populations in the Chicken Embryo. Immunobiology 1991, 182, 472-481. [CrossRef]

27. Koop, S.; Khokha, R.; Schmidt, E.E.; MacDonald, I.C.; Morris, V.L.; Chambers, A.F.; Groom, A.C. Overexpression of metalloproteinase inhibitor in B16F10 cells does not affect extravasation but reduces tumor growth. Cancer Res. 1994, 54, 4791-4797. [PubMed]

28. Schneider-Stock, R.; Ribatti, D. The CAM Assay as an Alternative In Vivo Model for Drug Testing. Handb. Exp. Pharmacol. 2021, 265, 303-323. [CrossRef]

29. Chou, T.C. Drug Combination Studies and Their Synergy Quantification Using the Chou-Talalay Method. Cancer Res. 2010, 70, 440-446. [CrossRef]

30. Zackheim, H.S.; Kashani-Sabet, M. Treatment of Cutaneous T Cell Lymphoma: Current Status and Future Directions. Am. J. Clin. Dermatol. 2002, 3, 103-119. [CrossRef]

31. Ramelyte, E.; Dummer, R.; Guenova, E. Investigative Drugs for the Treatment of Cutaneous T-Cell Lymphomas (CTCL): An Update. Expert Opin. Investig. Drugs 2019, 28, 799-809. [CrossRef] [PubMed]

32. Quoc Trung, L.; Espinoza, J.L.; Takami, A.; Nakao, S. Resveratrol Induces Cell Cycle Arrest and Apoptosis in Malignant NK Cells via JAK2/STAT3 Pathway Inhibition. PLoS ONE 2013, 8, e55183. [CrossRef]

33. Duvic, M.; Lemak, N.A.; Redman, J.R.; Eifel, P.J.; Tucker, S.L.; Cabanillas, F.F.; Kurzrock, R. Combined Modality Therapy for Cutaneous T-Cell Lymphoma. J. Am. Acad. Dermatol. 1996, 34, 1022-1029. [CrossRef]

34. Braverman, I.M.; Bruce Yager, N.; Chen, M.; Cadman, E.C.; Hait, W.N.; Maynard, T. Combined Total Body Electron Beam Irradiation and Chemotherapy for Mycosis Fungoides. J. Am. Acad. Dermatol. 1987, 16, 45-60. [CrossRef]

35. Winkler, C.F.; Sausville, E.A.; Ihde, D.C.; Fischmann, A.B.; Schechter, G.P.; Kumar, P.P.; Nibhanupdi, J.R.; Minna, J.D.; Makuch, R.W.; Eddy, J.L. Combined Modality Treatment of Cutaneous T Cell Lymphoma: Results of a 6-Year Follow-Up. J. Clin. Oncol. Off. J. Am. Soc. Clin. Oncol. 1986, 4, 1094-1100. [CrossRef]

36. Hallahan, D.E.; Griem, M.L.; Griem, S.F.; Medenica, M.; Soltani, K.; Lorincz, A.L.; Baron, J.M. Combined Modality Therapy for Tumor Stage Mycosis Fungoides: Results of a 10-Year Follow-Up. J. Clin. Oncol. Off. J. Am. Soc. Clin. Oncol. 1988, 6, 1177-1183. [CrossRef]

37. Kaye, F.J.; Bunn, P.A.; Steinberg, S.M.; Stocker, J.L.; Ihde, D.C.; Fischmann, A.B.; Glatstein, E.J.; Schechter, G.P.; Phelps, R.M.; Foss, F.M.; et al. A Randomized Trial Comparing Combination Electron-Beam Radiation and Chemotherapy with Topical Therapy in the Initial Treatment of Mycosis Fungoides. N. Engl. J. Med. 1989, 321, 1784-1790. [CrossRef]

38. Zinzani, P.L.; Baliva, G.; Magagnoli, M.; Bendandi, M.; Modugno, G.; Gherlinzoni, F.; Orcioni, G.F.; Ascani, S.; Simoni, R.; Pileri, S.A.; et al. Gemcitabine Treatment in Pretreated Cutaneous T-Cell Lymphoma: Experience in 44 Patients. J. Clin. Oncol. Off. J. Am. Soc. Clin. Oncol. 2000, 18, 2603-2606. [CrossRef]

39. Wilson, L.D.; Jones, G.W.; Kim, D.; Rosenthal, D.; Christensen, I.R.; Edelson, R.L.; Heald, P.W.; Kacinski, B.M. Experience with Total Skin Electron Beam Therapy in Combination with Extracorporeal Photopheresis in the Management of Patients with Erythrodermic (T4) Mycosis Fungoides. J. Am. Acad. Dermatol. 2000, 43, 54-60. [CrossRef]

40. Wilson, L.D.; Licata, A.L.; Braverman, I.M.; Edelson, R.L.; Heald, P.W.; Feldman, A.M.; Kacinski, B.M. Systemic Chemotherapy and Extracorporeal Photochemotherapy for T3 and T4 Cutaneous T-Cell Lymphoma Patients Who Have Achieved a Complete Response to Total Skin Electron Beam Therapy. Int. J. Radiat. Oncol. Biol. Phys. 1995, 32, 987-995. [CrossRef]

41. Quirós, P.A.; Jones, G.W.; Kacinski, B.M.; Braverman, I.M.; Heald, P.W.; Edelson, R.L.; Wilson, L.D. Total Skin Electron Beam Therapy Followed by Adjuvant Psoralen/Ultraviolet-A Light in the Management of Patients with T1 and T2 Cutaneous T-Cell Lymphoma (Mycosis Fungoides). Int. J. Radiat. Oncol. Biol. Phys. 1997, 38, 1027-1035. [CrossRef]

42. Chinn, D.M.; Chow, S.; Kim, Y.H.; Hoppe, R.T. Total Skin Electron Beam Therapy with or without Adjuvant Topical Nitrogen Mustard or Nitrogen Mustard Alone as Initial Treatment of T2 and T3 Mycosis Fungoides. Int. J. Radiat. Oncol. Biol. Phys. 1999, 43, 951-958. [CrossRef]

43. Kaltoft, K.; Bisballe, S.; Rasmussen, H.F.; Thestrup-Pedersen, K.; Thomsen, K.; Sterry, W. A Continuous T-Cell Line from a Patient with Sézary Syndrome. Arch. Dermatol. Res. 1987, 279, 293-298. [CrossRef]

44. Kaltoft, K.; Bisballe, S.; Dyrberg, T.; Boel, E.; Rasmussen, P.B.; Thestrup-Pedersen, K. Establishment of Two Continuous T-Cell Strains from a Single Plaque of a Patient with Mycosis Fungoides. In Vitr. Cell. Dev. Biol. J. Tissue Cult. Assoc. 1992, 28A, 161-167. [CrossRef] [PubMed]

45. Charley, M.R.; Tharp, M.; Locker, J.; Deng, J.S.; Goslen, J.B.; Mauro, T.; McCoy, P.; Abell, E.; Jegasothy, B. Establishment of a Human Cutaneous T-Cell Lymphoma in C.B-17 SCID Mice. J. Investig. Dermatol. 1990, 94, 381-384. [CrossRef] [PubMed]

46. Thaler, S.; Burger, A.M.; Schulz, T.; Brill, B.; Bittner, A.; Oberholzer, P.A.; Dummer, R.; Schnierle, B.S. Establishment of a Mouse Xenograft Model for Mycosis Fungoides. Exp. Dermatol. 2004, 13, 406-412. [CrossRef] 
47. Beylot-Barry, M.; Sibaud, V.; Thiebaut, R.; Vergier, B.; Beylot, C.; Delaunay, M.; Chene, G.; Dubus, P.; Merlio, J.P. Evidence That an Identical T Cell Clone in Skin and Peripheral Blood Lymphocytes Is an Independent Prognostic Factor in Primary Cutaneous T Cell Lymphomas. J. Investig. Dermatol. 2001, 117, 920-926. [CrossRef]

48. Andrique, L.; Poglio, S.; Prochazkova-Carlotti, M.; Kadin, M.E.; Giese, A.; Idrissi, Y.; Beylot-Barry, M.; Merlio, J.P.; Chevret, E. Intrahepatic Xenograft of Cutaneous T-Cell Lymphoma Cell Lines: A Useful Model for Rapid Biological and Therapeutic Evaluation. Am. J. Pathol. 2016, 186, 1775-1785. [CrossRef]

49. Begley, C.G.; Ellis, L.M. Drug Development: Raise Standards for Preclinical Cancer Research. Nature 2012, 483, 531-533. [CrossRef]

50. Perrin, S. Preclinical Research: Make Mouse Studies Work. Nature 2014, 507, 423-425. [CrossRef]

51. Ribatti, D.; Annese, T.; Tamma, R. The Use of the Chick Embryo CAM Assay in the Study of Angiogenic Activiy of Biomaterials. Microvasc. Res. 2020, 131, 104026. [CrossRef] [PubMed]

52. Naik, M.; Brahma, P.; Dixit, M. A Cost-Effective and Efficient Chick Ex-Ovo CAM Assay Protocol to Assess Angiogenesis. Methods Protoc. 2018, 1, 19. [CrossRef] [PubMed]

53. Nebbioso, A.; Dell'Aversana, C.; Bugge, A.; Sarno, R.; Valente, S.; Rotili, D.; Manzo, F.; Teti, D.; Mandrup, S.; Ciana, P.; et al. HDACs Class II-Selective Inhibition Alters Nuclear Receptor-Dependent Differentiation. J. Mol. Endocrinol. 2010, 45, $219-228$. [CrossRef] [PubMed]

54. Benedetti, R.; Conte, M.; Altucci, L. Targeting Histone Deacetylases in Diseases: Where Are We? Antioxid. Redox Signal. 2015, 23, 99-126. [CrossRef] [PubMed]

55. Thomas, S.J.; Snowden, J.A.; Zeidler, M.P.; Danson, S.J. The Role of JAK/STAT Signalling in the Pathogenesis, Prognosis and Treatment of Solid Tumours. Br. J. Cancer 2015, 113, 365-371. [CrossRef] [PubMed]

56. Wang, Y.; Fiskus, W.; Chong, D.G.; Buckley, K.M.; Natarajan, K.; Rao, R.; Joshi, A.; Balusu, R.; Koul, S.; Chen, J.; et al. Cotreatment with Panobinostat and JAK2 Inhibitor TG101209 Attenuates JAK2V617F Levels and Signaling and Exerts Synergistic Cytotoxic Effects against Human Myeloproliferative Neoplastic Cells. Blood 2009, 114, 5024-5033. [CrossRef]

57. Lafave, L.M.; Levine, R.L. JAK2 the Future: Therapeutic Strategies for JAK-Dependent Malignancies. Trends Pharmacol. Sci. 2012, 33, 574-582. [CrossRef]

58. Fiskus, W.; Verstovsek, S.; Manshouri, T.; Rao, R.; Balusu, R.; Venkannagari, S.; Nalabothula, N.R.; Ha, K.; Smith, J.E.; Hembruff, S.L.; et al. Heat Shock Protein 90 Inhibitor Is Synergistic with JAK2 Inhibitor and Overcomes Resistance to JAK2-TKI in Human Myeloproliferative Neoplasm Cells. Clin. Cancer Res. Off. J. Am. Assoc. Cancer Res. 2011, 17, 7347-7358. [CrossRef]

59. Bolden, J.E.; Peart, M.J.; Johnstone, R.W. Anticancer Activities of Histone Deacetylase Inhibitors. Nat. Rev. Drug Discov. 2006, 5, 769-784. [CrossRef]

60. Nolan, L.; Johnson, P.W.M.; Ganesan, A.; Packham, G.; Crabb, S.J. Will Histone Deacetylase Inhibitors Require Combination with Other Agents to Fulfil Their Therapeutic Potential? Br. J. Cancer 2008, 99, 689-694. [CrossRef]

61. Suraweera, A.; O'Byrne, K.J.; Richard, D.J. Combination Therapy with Histone Deacetylase Inhibitors (HDACi) for the Treatment of Cancer: Achieving the Full Therapeutic Potential of HDACi. Front. Oncol. 2018, 8, 92. [CrossRef] [PubMed]

62. Lindemann, R.K.; Gabrielli, B.; Johnstone, R.W. Histone-deacetylase inhibitors for the treatment of cancer. Cell Cycle 2004, 3, 777-786. [CrossRef]

63. Verstovsek, S.; Gotlib, J.; Mesa, R.A.; Vannucchi, A.M.; Kiladjian, J.J.; Cervantes, F.; Harrison, C.N.; Paquette, R.; Sun, W.; Naim, A.; et al. Long-Term Survival in Patients Treated with Ruxolitinib for Myelofibrosis: COMFORT-I and -II Pooled Analyses. J. Hematol. Oncol. 2017, 10, 156. [CrossRef] [PubMed]

64. Mazzacurati, L.; Lambert, Q.T.; Pradhan, A.; Griner, L.N.; Huszar, D.; Reuther, G.W. The PIM Inhibitor AZD1208 Synergizes with Ruxolitinib to Induce Apoptosis of Ruxolitinib Sensitive and Resistant JAK2-V617F-Driven Cells and Inhibit Colony Formation of Primary MPN Cells. Oncotarget 2015, 6, 40141-40157. [CrossRef]

65. Pérez, C.; González-Rincón, J.; Onaindia, A.; Almaráz, C.; García-Díaz, N.; Pisonero, H.; Curiel-Olmo, S.; Gómez, S.; Cereceda, L.; Madureira, R.; et al. Mutated JAK Kinases and Deregulated STAT Activity Are Potential Therapeutic Targets in Cutaneous T-Cell Lymphoma. Haematologica 2015, 100, e450-e453. [CrossRef]

66. Civallero, M.; Cosenza, M.; Pozzi, S.; Sacchi, S. Ruxolitinib Combined with Vorinostat Suppresses Tumor Growth and Alters Metabolic Phenotype in Hematological Diseases. Oncotarget 2017, 8, 103797. [CrossRef]

67. Brunetto, A.T.; Ang, J.E.; Lal, R.; Olmos, D.; Molife, L.R.; Kristeleit, R.; Parker, A.; Casamayor, I.; Olaleye, M.; Mais, A.; et al. First-in-Human, Pharmacokinetic and Pharmacodynamic Phase I Study of Resminostat, an Oral Histone Deacetylase Inhibitor, in Patients with Advanced Solid Tumors. Clin. Cancer Res. Off. J. Am. Assoc. Cancer Res. 2013, 19, 5494-5504. [CrossRef]

68. Yumeen, S.; Mirza, F.N.; Lewis, J.M.; King, A.L.O.; Kim, S.R.; Carlson, K.R.; Umlauf, S.R.; Surovtseva, Y.V.; Foss, F.M.; Girardi, M. JAK Inhibition Synergistically Potentiates BCL2, BET, HDAC, and Proteasome Inhibition in Advanced CTCL. Blood Adv. 2020, 4, 2213-2226. [CrossRef]

69. Levidou, G.; Siakantaris, M.; Papadaki, T.; Papadavid, E.; Vassilakopoulos, T.P.; Angelopoulou, M.K.; Marinos, L.; Nikolaou, V.; Economidi, A.; Antoniou, C.; et al. A Comprehensive Immunohistochemical Approach of AKT/MTOR Pathway and p-STAT3 in Mycosis Fungoides. J. Am. Acad. Dermatol. 2013, 69, 375-384. [CrossRef]

70. Papadavid, E.; Korkolopoulou, P.; Levidou, G.; Saetta, A.A.; Papadaki, T.; Siakantaris, M.; Nikolaou, V.; Oikonomidi, A.; Chatziandreou, I.; Marinos, L.; et al. In Situ Assessment of PI3K and PTEN Alterations in Mycosis Fungoides: Correlation with Clinicopathological Features. Exp. Dermatol. 2014, 23, 931-933. [CrossRef] 
71. de Masson, A.; O’Malley, J.T.; Elco, C.P.; Garcia, S.S.; Divito, S.J.; Lowry, E.L.; Tawa, M.; Fisher, D.C.; Devlin, P.M.; Teague, J.E.; et al. High-Throughput Sequencing of the T Cell Receptor $\beta$ Gene Identifies Aggressive Early-Stage Mycosis Fungoides. Sci. Transl. Med. 2018, 10, eaar5894. [CrossRef] [PubMed]

72. Campbell, J.J.; Clark, R.A.; Watanabe, R.; Kupper, T.S. Sezary Syndrome and Mycosis Fungoides Arise from Distinct T-Cell Subsets: A Biologic Rationale for Their Distinct Clinical Behaviors. Blood 2010, 116, 767-771. [CrossRef] [PubMed]

73. Barrio, S.; Gallardo, M.; Arenas, A.; Ayala, R.; Rapado, I.; Rueda, D.; Jimenez, A.; Albizua, E.; Burgaleta, C.; Gilsanz, F.; et al. Inhibition of Related JAK/STAT Pathways with Molecular Targeted Drugs Shows Strong Synergy with Ruxolitinib in Chronic Myeloproliferative Neoplasm. Br. J. Haematol. 2013, 161, 667-676. [CrossRef] [PubMed] 